\title{
¿Seasonal Variability of Subthermocline Eddy Kinetic Energy East of the Philippines
}

\author{
LinLIN Zhang, ${ }^{\mathrm{a}, \mathrm{b}, \mathrm{c}}$ YUChaO Hui, ${ }^{\mathrm{a}, \mathrm{d}}$ TANGDONG Qu, ${ }^{\mathrm{e}}$ AND DUNXIN Hu ${ }^{\mathrm{a}, \mathrm{b}, \mathrm{c}}$ \\ ${ }^{\text {a }}$ Key Laboratory of Ocean Circulation and Waves, Institute of Oceanology, Chinese Academy of Sciences, Qingdao, China \\ ${ }^{\mathrm{b}}$ Pilot National Laboratory for Marine Science and Technology (Qingdao), Qingdao, China \\ ${ }^{\mathrm{c}}$ Center for Ocean Mega-Science, Chinese Academy of Sciences, Qingdao, China \\ ${ }^{\mathrm{d}}$ University of Chinese Academy of Sciences, Beijing, China \\ ${ }^{\mathrm{e}}$ Joint Institute for Regional Earth System Science and Engineering, University of California, Los Angeles, Los Angeles, California
}

(Manuscript received 12 May 2020, in final form 27 November 2020)

\begin{abstract}
Seasonal modulation of subthermocline eddy kinetic energy (EKE) east of the Philippines and its associated dynamics are studied, using mooring measurements and outputs from an eddy-resolving ocean general circulation model for the period from 2000 to 2017. Significantly high EKE appears below the thermocline in the latitude band between $5^{\circ}$ and $14^{\circ} \mathrm{N}$ east of the Philippines. Separated by $10^{\circ} \mathrm{N}$, the EKE in the northern and southern parts of the region shows nearly opposite seasonal cycles, with its magnitude reaching a maximum in early spring and minimum in summer in the northern part and reaching a maximum in summer and minimum in winter in the southern part of the region. Further investigation indicates that both baroclinic and barotropic instabilities are essential in generating the subthermocline eddies, but the seasonal variation of subthermocline EKE is mainly caused by the seasonal modulation of barotropic instability. The seasonal modulation of barotropic instability in the northern and southern part of the region is associated with the seasonal evolution of North Equatorial Undercurrent and Halmahera Eddy, respectively.
\end{abstract}

KEYWORDS: Pacific Ocean; Boundary currents; Mesoscale processes; Eddies; Seasonal variability

\section{Introduction}

The western tropical Pacific is characterized by a complex current system (Fig. 1). The North Equatorial Current (NEC) flows westward, bifurcating into the northward-flowing Kuroshio and the southward-flowing Mindanao Current (MC) at approximately $14^{\circ} \mathrm{N}$ east of the Philippine coast (e.g., Fine et al. 1994; Lukas et al. 1996; Qu and Lukas 2003). Below the surface layer, the Luzon Undercurrent (LUC), Mindanao Undercurrent (MUC), and North Equatorial Undercurrent (NEUC) flow in the opposite direction to the Kuroshio, MC, and NEC, respectively (e.g., Lukas et al. 1996; Hu et al. 2015; Wang et al. 2015; Qiu et al. 2015; Hu et al. 2020). The complex three-dimensional current system provides warm beds for the generation of mesoscale eddies. Early hydrographic observations have shown features of subthermocline eddies east of the Philippine coast (e.g., Firing et al. 2005; Dutrieux 2009). Recent mooring acoustic Doppler current profiler (ADCP) measurements provide further evidence for the existence of these subthermocline eddies (e.g., Zhang et al. 2014, 2017). Significant intraseasonal signals in velocity, with a typical period of 60-120 days and a maximum velocity of $50 \mathrm{~cm} \mathrm{~s}^{-1}$, were identified in the subthermocline east of the Philippine coast. Zhang et al. (2017) attributed these intraseasonal signals to the generation and movement of subthermocline eddies.

Subthermocline eddies with their core or maximum velocity below the thermocline represent a special class of ocean eddies

¿ Denotes content that is immediately available upon publication as open access.

Corresponding author: Linlin Zhang, zhanglinlin@qdio.ac.cn that are different from the traditional surface mesoscale eddies, and are believed to play an important role in the transportation of salt and heat in the ocean (e.g., Qu et al. 2012; Pelland et al. 2013; Nan et al. 2017). Compared with surface mesoscale eddies, subthermocline eddies cannot be easily captured by satellite altimeter. Therefore, most previous studies of the subthermocline eddies east of the Philippine coast were based on eddy-resolving model products (e.g., Qu et al. 2012; Chiang and Qu 2013; Wang et al. 2014; Chiang et al. 2015; L. J. Chen et al. 2015; Xu et al. 2019), with only a few using limited mooring measurements as mentioned above (Zhang et al. 2014, 2017).

Based on model outputs from the OGCM for the Earth Simulator (OFES), Dutrieux (2009) noted that subthermocline eddies in the western Pacific are intrinsic to ocean. Later analysis of OFES outputs also indicated that there were more anticyclonic subthermocline eddies than cyclonic subthermocline eddies in the western tropical Pacific, and about $89 \%$ detected subthermocline eddies were nonlinear for at least half of their lifespan (Xu et al. 2019). Qu et al. (2012) and Zhang et al. (2014) pointed out that the east coast of the Philippines is featured with the highest subthermocline eddy kinetic energy (EKE) in the northwestern tropical Pacific. There are at least two groups of subthermocline eddies along the Philippine coast: one originates from the east with a dominant period of about 67 days, and another originates from the equatorial South Pacific Ocean with a typical period of 50-60 days (Chiang and Qu 2013; Chiang et al. 2015). It was proposed that the interaction between the complex current system and bottom topography was responsible for the generation of these subthermocline eddies (Chiang et al. 2015). Wang et al. (2014) and Chiang et al. (2015) further suggested that both baroclinic instability and barotropic instability were important to the 


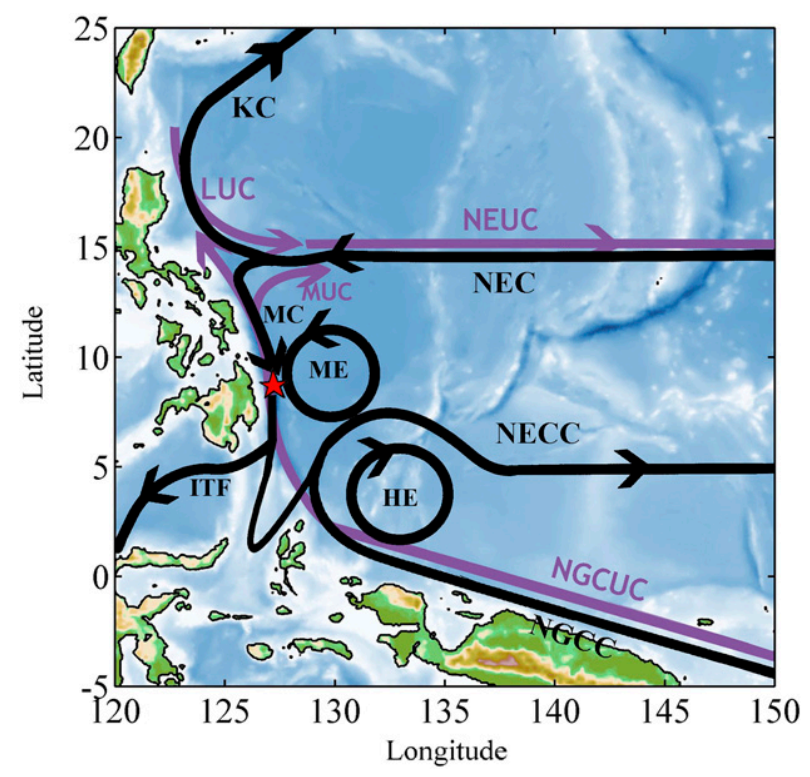

FIG. 1. Schematic diagram of the western Pacific Ocean circulation (replotted after Fine et al. 1994; Hu et al. 2015); the red star denotes the mooring location at $8^{\circ} \mathrm{N}, 127^{\circ} \mathrm{E}$.

generation of subthermocline eddies in the western tropical Pacific.

Generally speaking, previous studies of the subthermocline eddies east of the Philippine coast were mainly focused on their statistical characteristics such as radius, period, lifespan, and trajectories, while a couple of others investigated their source and generation. However, the quantitative contribution from baroclinic and barotropic instability to the generation of subthermocline eddies is still unclear, and the spatiotemporal variability of the subthermocline EKE east of the Philippine coast also remains unexplored. Here, we investigate the distribution and spatiotemporal variation of the subthermocline EKE east of the Philippines, using OFES outputs combined with mooring ADCP measurements. Barotropic instability is found to play a dominant role in the generation of subthermocline eddies east of the Mindanao Island. Significant seasonal variability is revealed in the subthermocline EKE, largely due to the seasonal modulation of barotropic instability.

The paper is organized as follows. A brief description of the data and methods of analysis is given in section 2 . The model outputs are compared with mooring observations in section 3 . The vertical distribution of EKE and the seasonal variation of subthermocline EKE east of the Philippine coast are presented in sections 4 and 5, respectively. Dynamic processes governing the generation and seasonal modulation of subthermocline EKE are investigated in section 6, and a summary and discussion are given in section 7 .

\section{Data and method of analysis}

\section{a. OFES model outputs}

Outputs from the Oceanic General Circulation Model for the Earth Simulator (OFES) are used in this study to investigate the subthermocline EKE and its spatiotemporal variation east of the Philippine coast. The OFES model is based on the third version of Modular Ocean Model (MOM 3.0), and its domain covers a near-global region extending from $75^{\circ} \mathrm{S}$ to $75^{\circ} \mathrm{N}$, with a horizontal resolution of $0.1^{\circ}$ both in the longitude and latitude. There are 54 levels in depth and the vertical resolution varies from $5 \mathrm{~m}$ near the surface to $330 \mathrm{~m}$ near the bottom. The model is first spun up for 50 years, driven by annual mean temperature and salinity fields of the World Ocean Atlas 1998 (WOA98), and then, it is integrated from 1950 using daily surface wind stress, heat flux, and salinity flux forcing provided by the National Centers for Environmental Prediction (NCEP). The 3-day snapshot model outputs for the period of 2000-17 are used in this study. Detailed descriptions about this model can be found in Masumoto et al. (2004) and Sasaki et al. (2008).

\section{b. Subsurface mooring measurements}

Supported by the Northwestern Pacific Ocean Circulation and Climate Experiment (NPOCE) program, a subsurface mooring was deployed at about $8^{\circ} \mathrm{N}, 127^{\circ} \mathrm{E}$ east of the Mindanao Island to measure the MC/MUC. Two ADCPs $(75 \mathrm{kHz}$, Teledyne RD Instruments) were mounted on the mooring at about $400 \mathrm{~m}$, with one looking upward and another looking downward. These two ADCPs recorded nearly 4-yr velocity data from December 2010 to August 2014, and during this period the mooring was retrieved twice in July 2011 and December 2012 to collect data and replace batteries. Hourly velocity data recorded by the ADCP are first daily averaged to remove tidal signals and then interpolated onto pressure levels from 50 to $750 \mathrm{~m}$ with a vertical interval of $10 \mathrm{~m}$. More details of this mooring are available in Zhang et al. (2014). In addition, another two moorings at $8.5^{\circ} \mathrm{N}, 130^{\circ} \mathrm{E}$ and $12.5^{\circ} \mathrm{N}, 130^{\circ} \mathrm{E}$ are also used in this study to validate the OFES outputs. These two moorings have same configuration as the $8^{\circ} \mathrm{N}, 127^{\circ} \mathrm{E}$ mooring, and the ADCP measurements spans from September 2015 to November 2018 and from December 2016 to December 2018, respectively. Detailed information of these two moorings can be found in Zhang et al. (2017).

\section{c. Estimates of EKE and energy conversion rate}

To isolate kinetic energy variations induced by subthermocline eddies from background flow variations, velocity can be divided into two components:

$$
u(x, y, t)=\tilde{u}(x, y, t)+u^{\prime}(x, y, t)
$$

where $\tilde{u}$ and $u^{\prime}$ denote velocity signals with time scales longer and shorter than 150 days, respectively. Therefore, $u^{\prime}$ represents velocity fluctuations associated with subthermocline eddies, considering the fact that the intraseasonal variability caused by subthermocline eddies east of Philippines exhibits a dominant period of 60-120 days from both mooring measurements and OFES model outputs (Qu et al. 2012; Zhang et al. 2014). The velocity $u^{\prime}$ is then used to estimate EKE, according to formula (2):

$$
\mathrm{EKE}=\frac{1}{2}\left(u^{\prime 2}+v^{\prime 2}\right)
$$

Many previous studies have indicated that baroclinic and barotropic instability are two major mechanisms of the eddy 
(a) Meridional velocity of mooring $\mathrm{ADCP}$ at $8^{\circ} \mathrm{N}, 127^{\circ} \mathrm{E}$

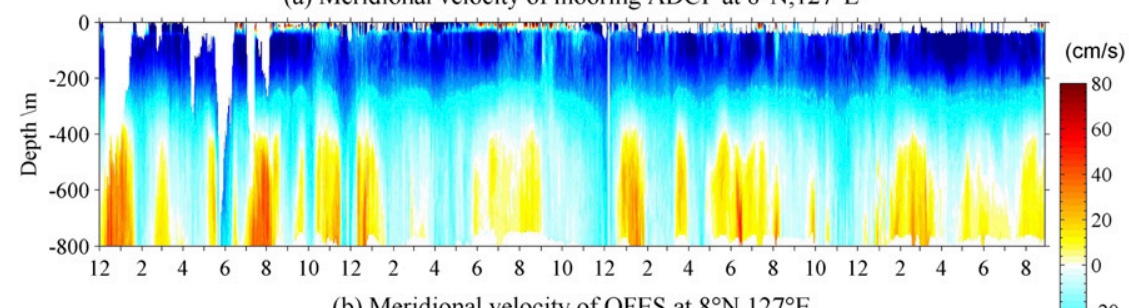

(b) Meridional velocity of OFES at $8^{\circ} \mathrm{N}, 127^{\circ} \mathrm{E}$

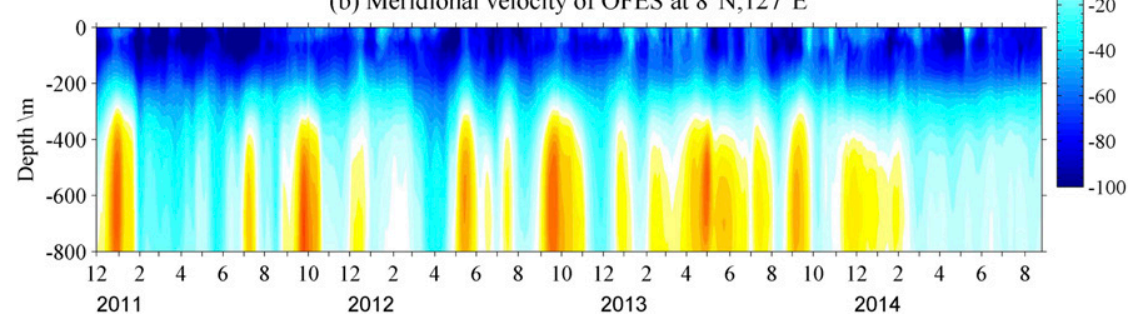

FIG. 2. Meridional velocity at $8^{\circ} \mathrm{N}, 127^{\circ} \mathrm{E}$ during December 2010 to August 2014 derived from

(a) mooring ADCP in a daily interval and (b) OFES in a 3-day interval.

generation in the western Pacific (e.g., Qiu 1999; Dutrieux 2009; Wang et al. 2014; Chiang et al. 2015; X. Chen et al. 2015). To evaluate the contribution of baroclinic and barotropic instability in generating subthermocline eddies and their variability east of the Philippine coast, we calculate local barotropic energy conversion rate (BTR) and baroclinic energy conversion rate (BCR) as follows,

$$
\begin{aligned}
& \mathrm{BTR}=-\left[u^{\prime} u^{\prime} \frac{\partial \tilde{u}}{\partial x}+u^{\prime} v^{\prime}\left(\frac{\partial \tilde{v}}{\partial x}+\frac{\partial \tilde{u}}{\partial y}\right)+v^{\prime} v^{\prime} \frac{\partial \tilde{v}}{\partial y}\right] \\
& \mathrm{BCR}=-\left(\frac{g}{\rho_{0}} \rho^{\prime} w^{\prime}\right),
\end{aligned}
$$

where $\rho^{\prime}$ and $w^{\prime}$ denote potential density and vertical velocity with time scales shorter than 150 days, while $g$ and $\rho_{0}$ are the gravity constant of $9.807 \mathrm{~m} \mathrm{~s}^{-2}$ and the background potential density of $1025 \mathrm{~kg} \mathrm{~m}^{-3}$, respectively. The obtained BTR and BCR will be used in the following analysis.

It should be noted that the calculation of BTR here is slightly different with some previous studies which adopts mean velocity to calculate the BTR (e.g., Chiang and Qu 2013; Wang et al. 2014; Qiu et al. 2015). In fact, these studies often focus on the energy transformation from the background mean flow to mesoscale eddies under the climatological condition, but this study focus on the seasonal variation of the energy transformation, which is related to the seasonally varying background flow. Therefore, we used the low-pass-filtered background flow $(\tilde{u})$ to calculate the seasonal cycle of BTR. A similar decomposition method has also been used in several previous studies to address the temporal variation of energy conversions (e.g., X. Chen et al. 2015; Zhu et al. 2018; Yang et al. 2020).

\section{Validation of OFES outputs}

The OFES outputs have been extensively used to investigate the structure and multiscale variations of oceanic currents and eddies in the western tropical Pacific, and the results have shown remarkable consistency with observations (e.g.,
Dutrieux 2009; Qu et al. 2012; Chiang and Qu 2013; Zhang et al. 2014; Wang et al. 2014; Chiang et al. 2015; Zhang et al. 2017; Xu et al. 2019). For example, Chiang and Qu (2013) compared the OFES (NCEP-run) outputs with mooring velocity in the upper $200 \mathrm{~m}$ at $2.5^{\circ} \mathrm{S}, 142^{\circ} \mathrm{E}$ from July 1995 to July 1996 and indicated that the model reproduced nearly all the observed features of velocity on seasonal time scale. Zhang et al. (2014) and Wang et al. (2014) compared the OFES (NCEP-run) outputs with 2 years of mooring observations east of the Mindanao Island at $8^{\circ} \mathrm{N}, 127^{\circ} \mathrm{E}$ and found that the model well captured the intraseasonal variability of velocity recorded by the mooring, except for some slight differences in magnitude. In this study, we also compare the modeled velocity with mooring ADCP measurements at $8^{\circ} \mathrm{N}, 127^{\circ} \mathrm{E}$ from December 2010 to August 2014, similar to Zhang et al. (2014) and Wang et al. (2014) but with two more years of time series (Fig. 2). Mooring ADCP record the strong southward-flowing MC in the upper $300 \mathrm{~m}$ during the whole period of observation with a maximum velocity of $\sim 120 \mathrm{~cm} \mathrm{~s}^{-1}$ in April 2014 at about $100 \mathrm{~m}$. Beneath the MC, the northward-flowing MUC is detected in the all-time mean field (figure not shown), with its core lying at around $600 \mathrm{~m}$, where significant intraseasonal variations are demonstrated. Generally speaking, all these observed features are captured by OFES. Even though the modeled intraseasonal signal may not match the observations case by case, it exhibits similar subthermocline features to the mooring records with comparable amplitude. Also, the seasonal variation of the subthermocline EKE simulated by the OFES model generally coincides with the mooring measurements, as shown in section 5 . Therefore, we think that the OFES outputs are reliable and well suited for investigating the ocean currents and eddy activities in the western tropical Pacific.

\section{Vertical distribution of EKE east of the Philippine coast}

Figures $3 \mathrm{a}$ and $3 \mathrm{~b}$ show the all-time mean EKE in the upper layer $(0-200 \mathrm{~m})$ and subthermocline layer $(300-700 \mathrm{~m})$, respectively, derived from OFES during 2000-17. An intriguing 
(a) Mean EKE in upper $200 \mathrm{~m}$

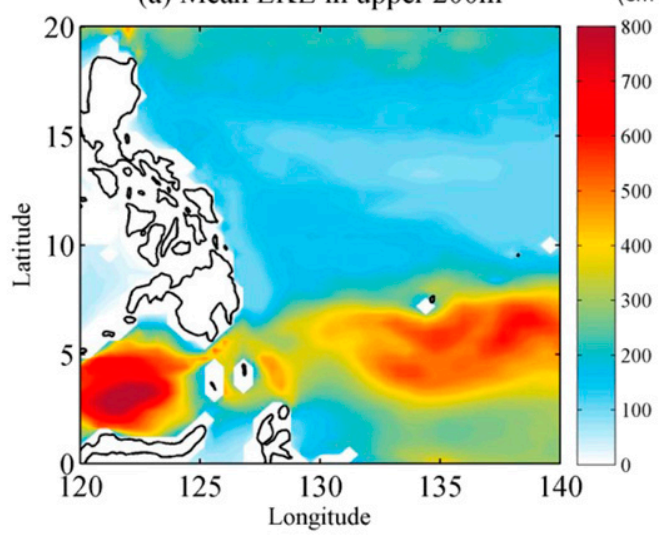

$\left(\mathrm{cm}^{2} / \mathrm{s}^{2}\right)$

(b) Mean EKE between 300-700m

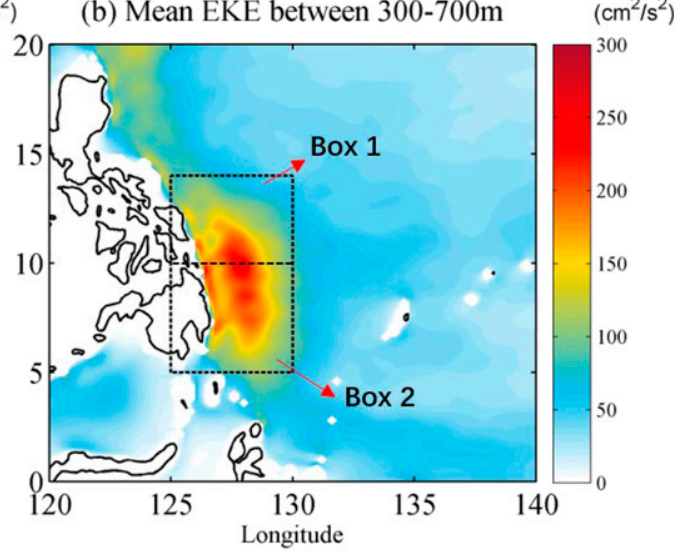

(c) Mean EKE between $9.5-10.5 \mathrm{~N}$

$\left(\mathrm{cm}^{2} / \mathrm{s}^{2}\right)$

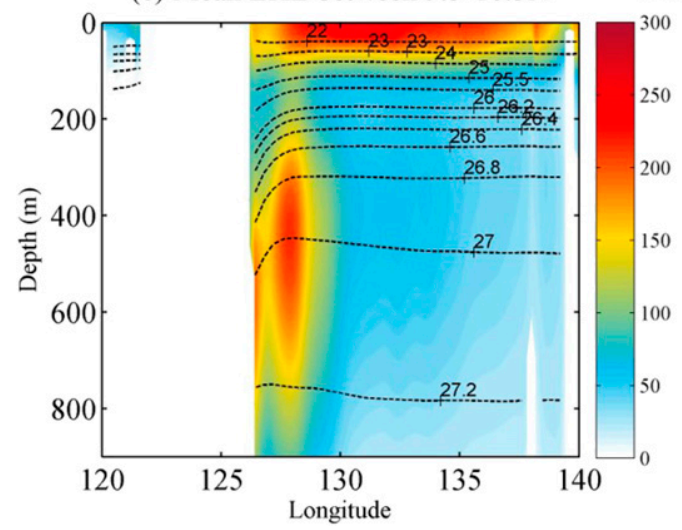

(d) Mean EKE between 127-128E

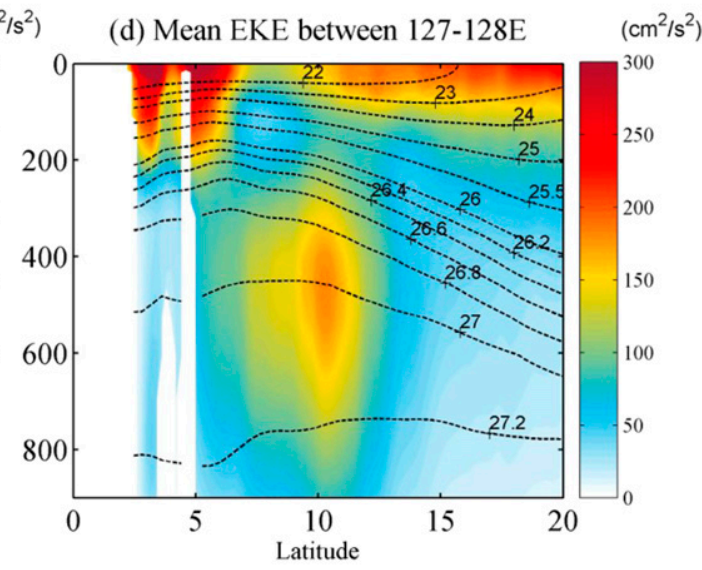

FIG. 3. All-time mean EKE $\left(\mathrm{cm}^{2} \mathrm{~s}^{-2}\right)$ calculated with 150-day high-pass-filtered velocity from OFES during 2000-2017: (a) vertically averaged in the upper $200 \mathrm{~m}$, (b) vertically averaged between 300 and $700 \mathrm{~m}$; (c) meridionally averaged between $9.5^{\circ}$ and $10.5^{\circ} \mathrm{N}$; (d) zonally averaged between $127^{\circ}$ and $128^{\circ} \mathrm{E}$.

phenomenon is that the EKE distributions in the subthermocline layer are totally different from that in the upper layer. Outside the Celebes Sea, high EKE in the upper layer mainly appears in the zonal band between $2^{\circ}$ and $8^{\circ} \mathrm{N}$ near the North Equatorial Countercurrent (NECC), which has been reported by previous studies based on satellite altimetry and OFES (X. Chen et al. 2015). High EKE in the subthermocline layer appears east of the Philippine coast between $5^{\circ}$ and $14^{\circ} \mathrm{N}$ (Fig. 3b). To show the vertical distribution of EKE, we select two sections crossing the high EKE (Figs. 3c,d). In a zonal direction averaged between $9.5^{\circ}$ and $10.5^{\circ} \mathrm{N}$, high EKE appears below the thermocline at depths between 200 and $850 \mathrm{~m}$, with its core lying at approximately $450 \mathrm{~m}$ and extending from the coast to about $128^{\circ} \mathrm{E}$. In a meridional section averaged between $127^{\circ}$ and $128^{\circ} \mathrm{E}$, high EKE is also seen below the thermocline, with its core lying at about $450 \mathrm{~m}$ near $10^{\circ} \mathrm{N}$ (Fig. 3d). The high EKE shown in both sections is largely invisible in the upper layer, suggesting its association with subthermocline eddies (e.g., Chiang and Qu 2013).

Based on 2 years of mooring ADCP measurements at $8^{\circ} \mathrm{N}$, $127^{\circ} \mathrm{E}$ east of the Mindanao Island during December 2010 and December 2012, Zhang et al. (2014) reported significant intraseasonal variations in the subthermocline with a period of
60-80 days. They related these intraseasonal variations to the subthermocline eddies in the region. Using the same dataset but with two more years of time series, we show the vertical profile of EKE calculated with the 150-day high-pass-filtered velocity (Fig. 4). The profile clearly demonstrates a vertical maximum of EKE $\left(\sim 130 \mathrm{~cm}^{2} \mathrm{~s}^{-2}\right)$ at about $650 \mathrm{~m}$, which is apparently isolated from the upper layer by a EKE minimum at 150-300 m. The linear regression coefficient of EKE at different depth relative to that at $650 \mathrm{~m}$ is also shown in Fig. 4. As expected, the regression coefficient is reduced gradually from 1.0 at $650 \mathrm{~m}$ to 0.0 at the sea surface. Below $650 \mathrm{~m}$, the coefficient also decreases with depth. This result indicates that mesoscale eddies associated with high EKE in the subthermocline have their strongest signal near $650 \mathrm{~m}$, confirming their characteristics of subthermocline eddies. The EKE profile and linear regression coefficient profile derived from OFES at the same location during the same period are also shown in Fig. 4. The modeled EKE and regression coefficient profile resemble the observations in both magnitude and shape. In a qualitative sense, the model simulates the observed subthermocline EKE well, though the depths of the EKE maximum and minimum simulated by the model are slightly shallower than those from the observations. This consistency further demonstrates the 


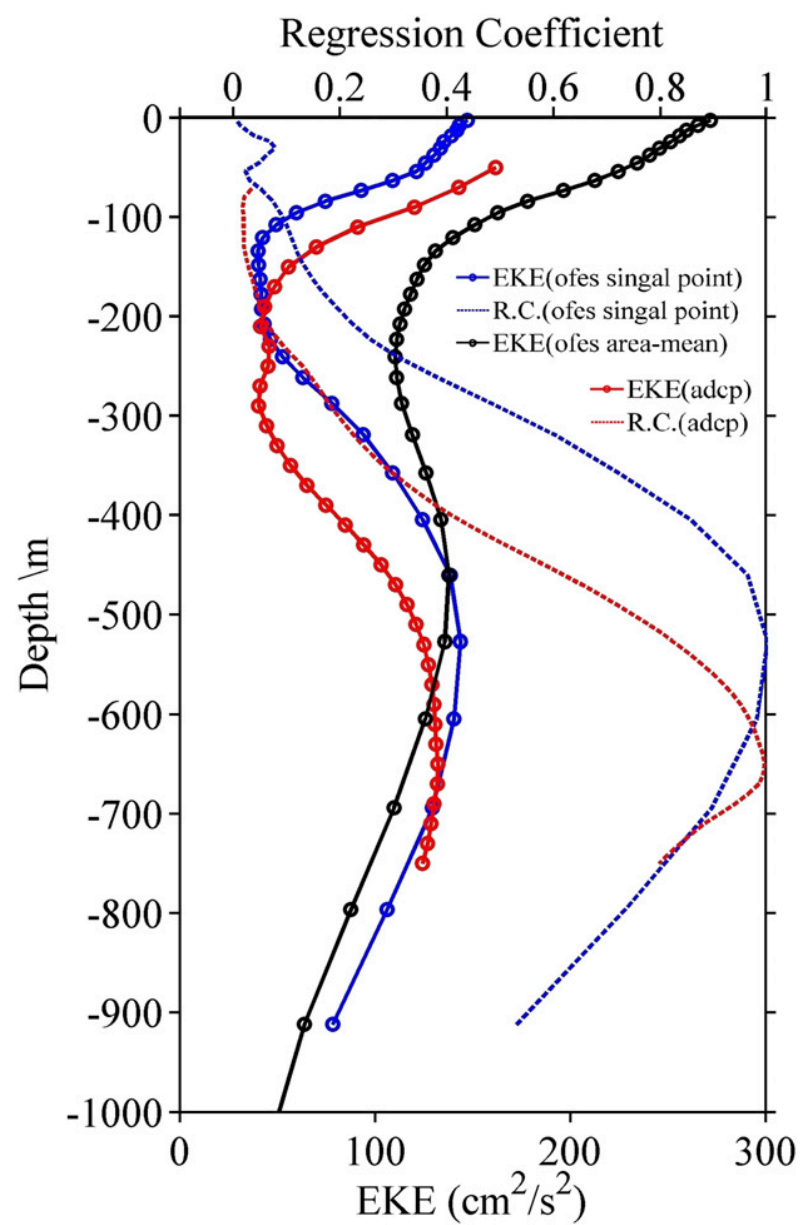

FIG. 4. EKE profiles calculated with velocity from mooring ADCP (red line) and OFES (blue line) at $8^{\circ} \mathrm{N}, 127^{\circ} \mathrm{E}$ during December $2010-$ August 2014 , and regional $\left(125^{\circ}-130^{\circ} \mathrm{E} ; 5^{\circ}-14^{\circ} \mathrm{N}\right)$ mean EKE profile calculated with OFES during 2000-17 (black line). The red (blue) dashed curve shows the linear correlation coefficient of EKE between time series at different depth and that at $650 \mathrm{~m}(520 \mathrm{~m})$ from mooring ADCP (OFES) at $8^{\circ} \mathrm{N}, 127^{\circ} \mathrm{N}$ during December 2010-August 2014.

capability of OFES in simulating the subthermocline eddy activities east of the Philippine coast. In addition, the regional mean EKE profile in the high subthermocline EKE region $\left(125^{\circ}-130^{\circ} \mathrm{E}, 5^{\circ}-14^{\circ} \mathrm{N}\right)$ east of the Philippine coast (Fig. $\left.3 \mathrm{~b}\right)$ is also presented in Fig. 4. This regional mean EKE profile exhibits essentially the same features as that at the mooring site. However, the regional mean profile appears smoother than the single point results, which might be due to the spatial distribution of the EKE. The generation mechanism of this high subthermocline EKE will be examined in section 6 .

\section{Seasonal variation of subthermocline EKE}

Figure 5 shows the seasonal variation of EKE at $8^{\circ} \mathrm{N}, 127^{\circ} \mathrm{E}$ derived from mooring measurements and OFES outputs during December 2010-August 2014. Mooring measurements demonstrate a significant semiannual oscillation in

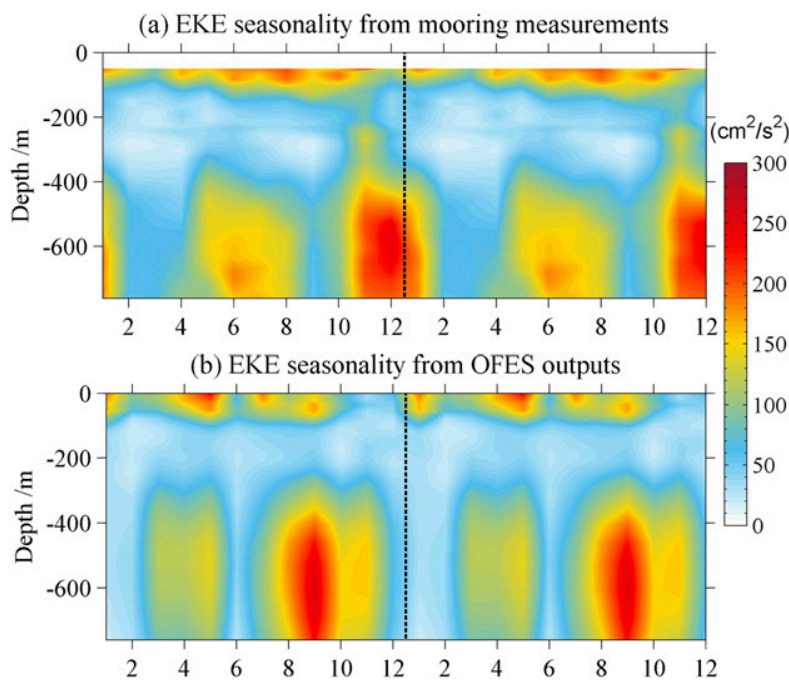

FIG. 5. Seasonal variation of EKE at $8^{\circ} \mathrm{N}, 127^{\circ} \mathrm{E}$ derived from (a) mooring measurements and (b) OFES outputs during December 2010-August 2014.

the subthermocline EKE, which peaks in June and December and weakens in March and September (Fig. 5a). Wang et al. (2016b) firstly reported this semiannual oscillation in the meridional velocity using the same mooring dataset. Similar to the mooring records, OFES model reproduces a semiannual oscillation signal in the subthermocline EKE, which is strong in May and September and weak in January and June (Fig. 5b). Nevertheless, it should be noted that the timing of the semiannual oscillation are slightly different, with the model results leading the mooring record by about 2 months. Detailed reason for this timing difference still remains unexplored, which will be investigated in future studies. Regardless of this timing difference, the seasonal variation of subthermocline EKE simulated by OFES generally coincides with the mooring record (Fig. 5).

To further investigate the seasonal variation of subthermocline EKE east of the Philippine coast, we show the monthly modulation of EKE averaged between 300 and $700 \mathrm{~m}$ and during the period 2000-17 from OFES (Fig. 6). Elevated subthermocline EKE appears all year round in the region east of the Philippine coast, as marked by the black box, and the EKE exhibits an obvious seasonally varying spatial pattern. Separated by $10^{\circ} \mathrm{N}$, the EKE in the northern and southern part of the region shows nearly opposite phases of the seasonal cycle. In the following, we refer the northern and southern part of the region as box 1 and box 2, respectively. The EKE in box 1 is relatively strong in boreal winter and early spring and pretty weak in summer. The EKE in box 2 reaches its maximum in late spring and summer and minimum in winter. To better demonstrate these differences in phase, monthly EKE anomalies relative to its multiyear mean value are presented in Fig. 7. For most of the time during the year, the monthly EKE anomalies in the two boxes show opposite signs. For example, the EKE anomalies during January-March are generally positive in box 1 but negative in box 2. Similarly, during May-September, the EKE anomalies are generally negative 
(a) Jan

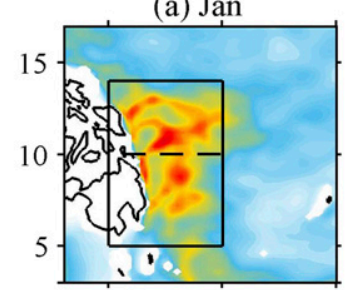

(e) May

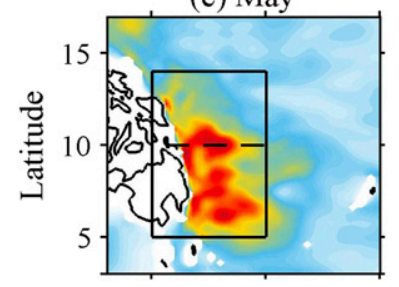

(i) Sep

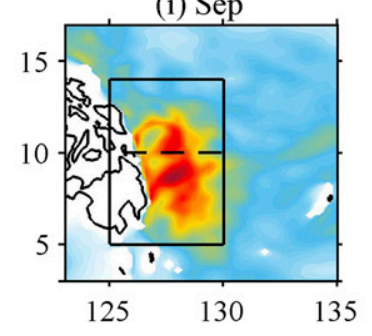

(b) Feb

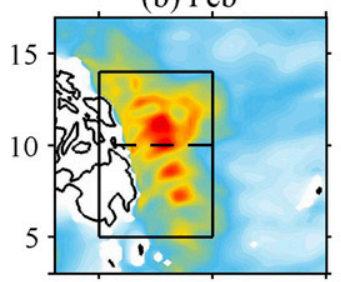

(f) Jun

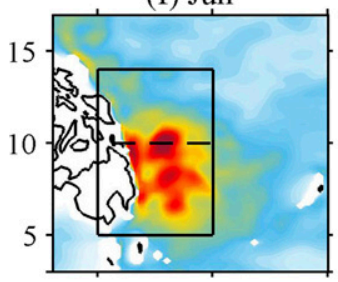

(g) Oct

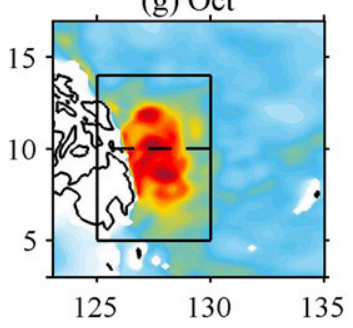

(c) Mar

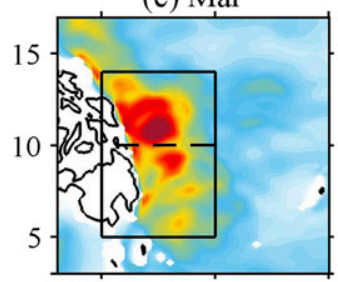

(g) Jul

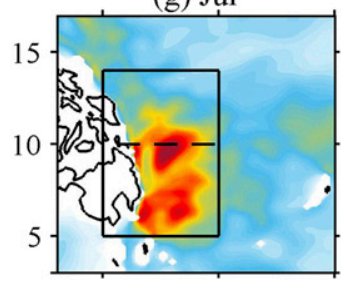

(k) Nov

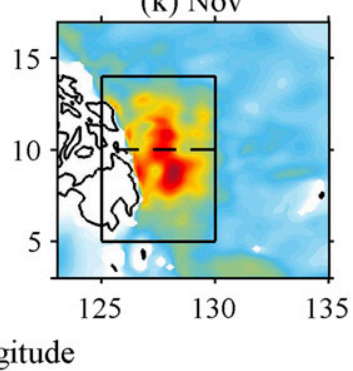

(d) Apr

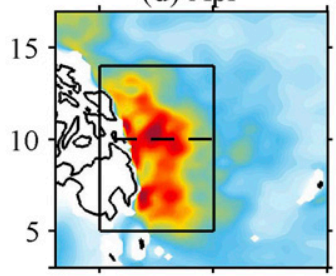

(h) Aug

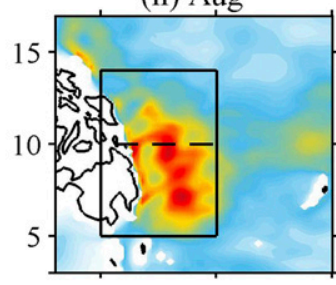

(1) Dec

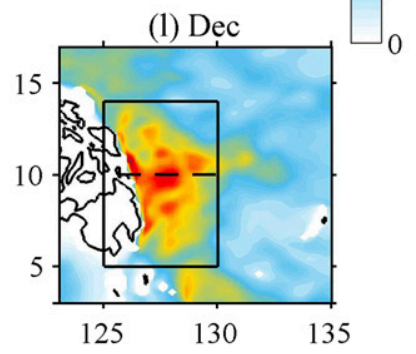
250 50 $\left(\mathrm{cm}^{2} / \mathrm{s}^{2}\right)$ 200 150 100

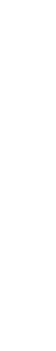

\section{Longitude}

FIG. 6. Monthly mean subthermocline EKE $(300-700 \mathrm{~m})$ calculated with OFES for the period 2000-17.

in box 1 but positive in box 2. Furthermore, an empirical orthogonal function (EOF) analysis is applied to the seasonal cycle of subthermocline EKE (Fig. 8). The first EOF mode captures about $38 \%$ of the total variance, which exhibits a prominent annual cycle east of the Philippine coast. The annual cycle of the EKE north and south of $10^{\circ} \mathrm{N}$ appears in opposite phase, confirming the opposite seasonal cycle of subthermocline EKE in box 1 and box 2 mentioned above.

To clearly show the seasonality of EKE in box 1 and box 2, regional mean subthermocline EKE in each box is also calculated for each month (Fig. 9). Consistent with the results mentioned above, the EKE in box 1 peaks to $140 \mathrm{~cm}^{2} \mathrm{~s}^{-2}$ in March, and decreases to a minimum of $88 \mathrm{~cm}^{2} \mathrm{~s}^{-2}$ in July. The EKE seasonal variability in box 2 shows nearly an opposite phase to that in box 1 , reaching its maximum $\left(\sim 124 \mathrm{~cm}^{2} \mathrm{~s}^{-2}\right)$ in July and minimum $\left(\sim 87 \mathrm{~cm}^{2} \mathrm{~s}^{-2}\right)$ in February. Note that we exclude the velocity of 2003 from the calculation of subthermocline EKE, because the EKE simulated by OFES is extremely high in September 2003 and including it in the calculation would significantly change the mean seasonal cycle for the period 2000-17. The causes for this extremely high EKE in September 2003 are not clear and need to be investigated by further research.

Another interesting phenomenon that is worth noting is that the EKE seasonality revealed by both mooring observations and OFES outputs at the mooring site (Fig. 5) differs obviously from the regional mean seasonality in box 2 east of the Mindanao Island (Fig. 9). Semiannual oscillation seems to dominate the seasonality of EKE at the mooring site, while an annual cycle dominates the regional mean EKE in box 2. To interpret this difference, a harmonic analysis is applied to the monthly mean subthermocline EKE east of the Philippine coast, and the amplitudes of annual and semiannual signals are shown in Fig. 10. The results indicate that annual signal is dominant in both box 1 and box 2, while the semiannual signal is much weaker and only located in a small area northeast of the Mindanao Island. However, at the mooring site $\left(8^{\circ} \mathrm{N}\right.$, $127^{\circ} \mathrm{E}$ ) as shown by the red star in Fig. 10, the annual signal has a very small amplitude, which makes the moderate semiannual signal become significant at this location. Therefore, the spatial pattern and amplitude difference between the annual and semiannual signals explain the different seasonality of the subthermocline EKE between the mooring site (Fig. 5) and Box 2 east of the Mindanao Island (Fig. 9).

To verify the spatial difference of subthermocline EKE seasonality as illustrated by the harmonic analysis, we analyzed the ADCP measurements from another two moorings deployed at $8.5^{\circ} \mathrm{N}, 130^{\circ} \mathrm{E}$ and $12.5^{\circ} \mathrm{N}, 130^{\circ} \mathrm{E}$ by the NPOCE program (Fig. 10). The monthly mean subthermocline EKE averaged between 300 and $700 \mathrm{~m}$ is derived from the mooring ADCP measurements, and the model results at the same locations are also shown for comparison (Fig. 11). Generally speaking, the seasonality of subthermocline EKE observed by these two moorings is dominated by the annual cycle, and the OFES model appears to capture this annual cycle, agreeing well with the mooring observations despite the differences in 
(a) Jan

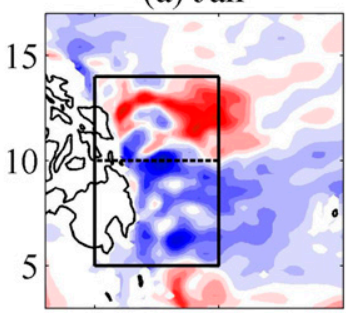

(e) May

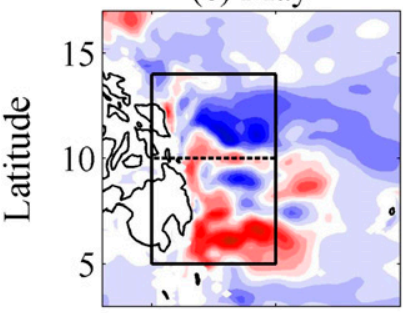

(i) Sep

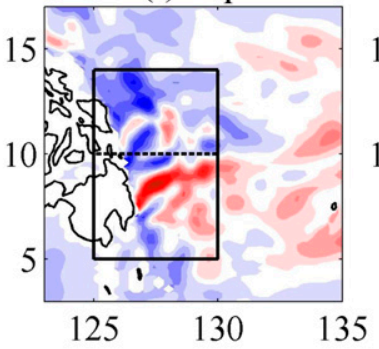

(b) Feb

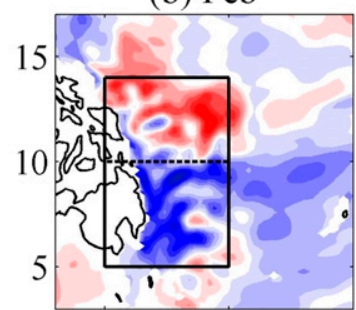

(f) Jun

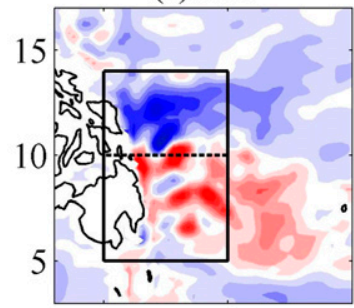

(j) Oct

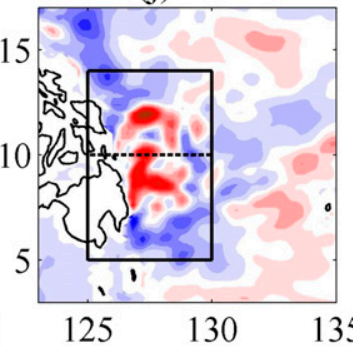

(c) Mar

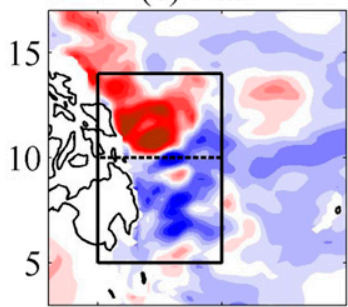

(g) Jul

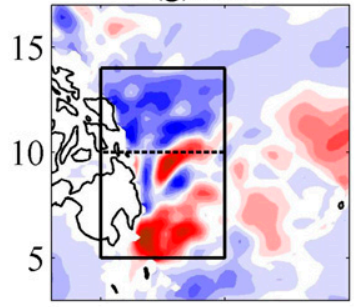

(k) Nov

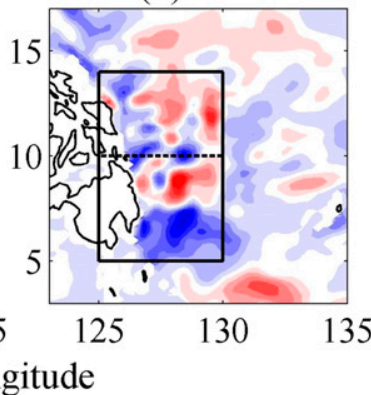

(d) Apr

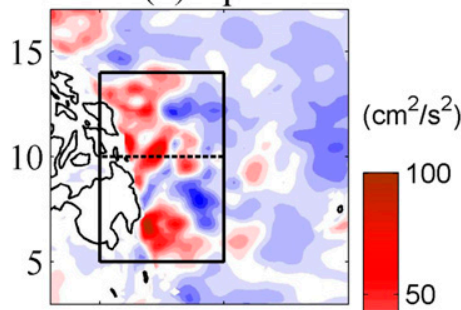

(h) Aug

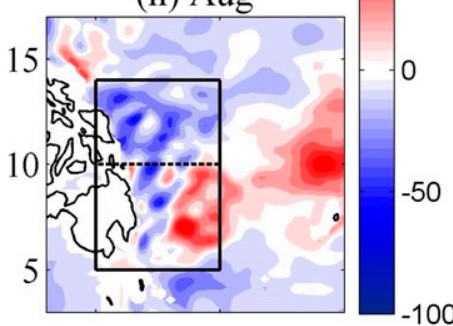

(1) Dec

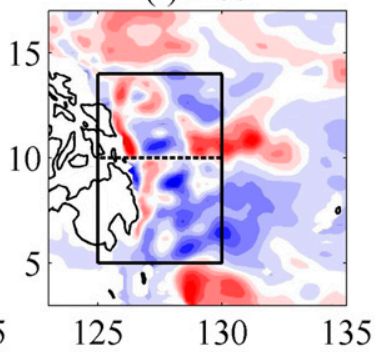

FIG. 7. Monthly subthermocline EKE anomalies (300-700 m) relative to its multiyear (2000-17) mean value from OFES.

magnitude. At $12.5^{\circ} \mathrm{N}, 130^{\circ} \mathrm{E}$, the correlation of subthermocline EKE seasonality between the mooring measurements and model results reaches 0.73 (Fig. 11b), confirming the capability of OFES in simulating the seasonal variation of subthermocline
EKE in this area. Meanwhile, the dominant annual cycle of subthermocline EKE observed at $8.5^{\circ} \mathrm{N}, 130^{\circ} \mathrm{E}$ and $12.5^{\circ} \mathrm{N}$, $130^{\circ} \mathrm{E}$ combined with the dominant semiannual oscillation observed at $8^{\circ} \mathrm{N}, 127^{\circ} \mathrm{E}$ confirms above harmonic analysis that

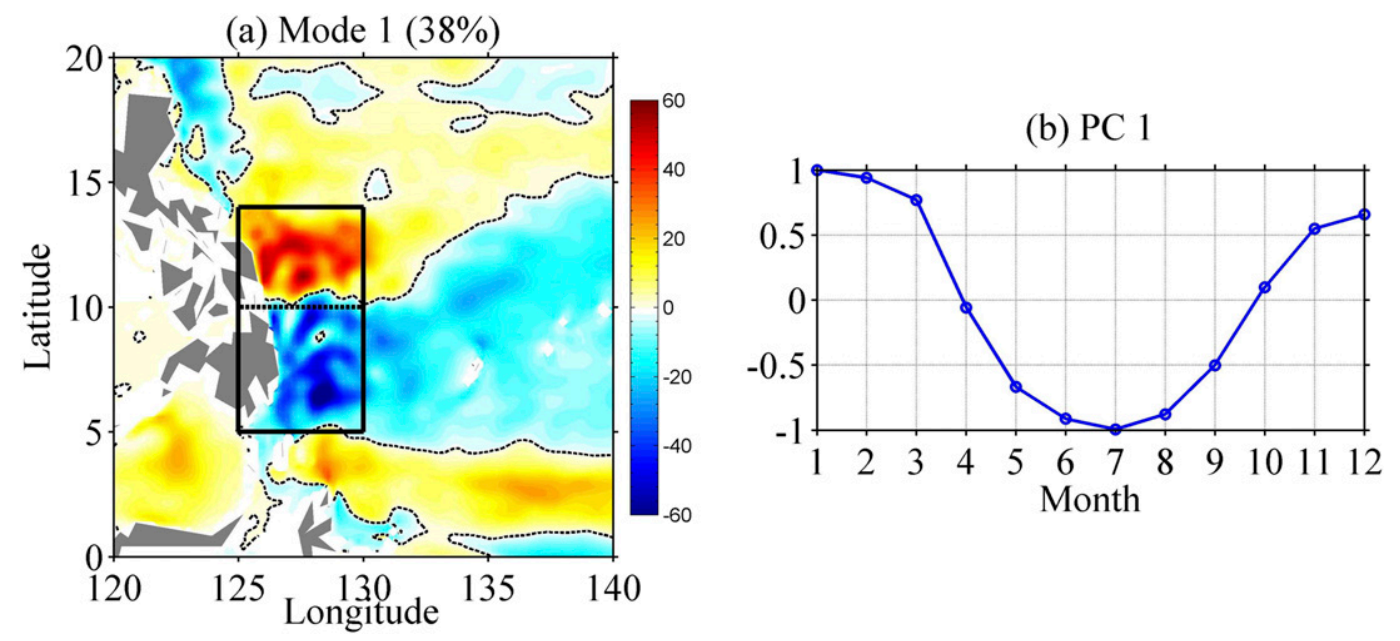

FIG. 8. (a) Spatial pattern and (b) time series associated with the first EOF mode of the monthly mean subthermocline EKE east of the Philippine coast from OFES. 


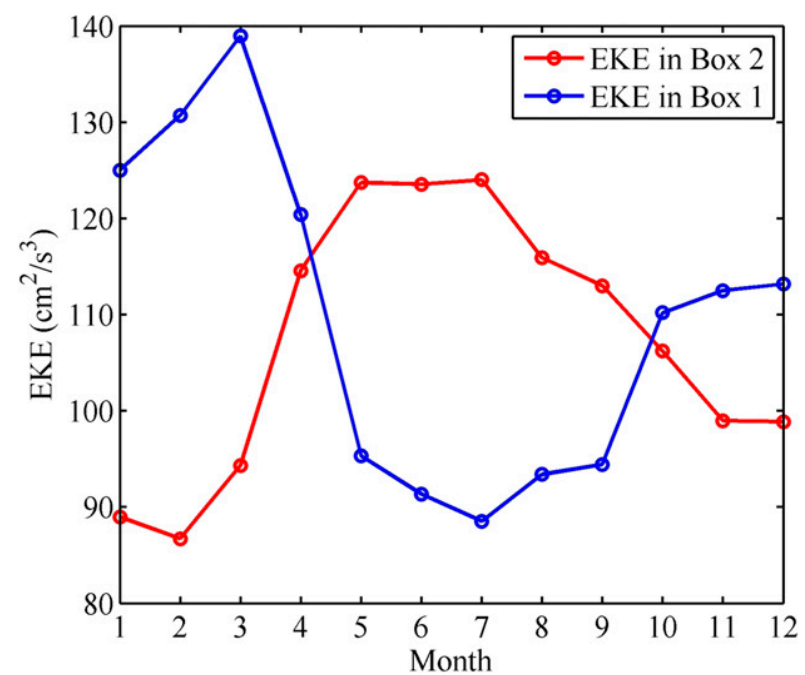

FIG. 9. Seasonal variation of regional mean subthermocline EKE in box 1 (blue; $125^{\circ}-130^{\circ} \mathrm{E}, 10^{\circ}-14^{\circ} \mathrm{N}$ ) and box 2 (red; $125^{\circ}-130^{\circ} \mathrm{E}$, $5^{\circ}-10^{\circ} \mathrm{N}$ ) from OFES during 2000-17.

the seasonal variation of subthermocline EKE east of the Philippines is dominant by the annual cycle and the semiannual oscillation is just a local phenomenon (Fig. 10).

\section{Governing processes of subthermocline EKE and its seasonal modulation}

Current instability is a key process generating mesoscale eddies in the ocean (e.g., Chelton et al. 1998; Qiu 1999). Many previous studies have emphasized the role of baroclinic instability in eddy generation east of the Philippine coast (e.g., Dutrieux 2009; Qiu et al. 2015; Wang et al. 2016a; Hu et al. 2018). Several others also noticed the importance of barotropic instability and proposed that both barotropic and baroclinic instabilities are at work in generating the subthermocline (a) Seasonality of subthermocline EKE at $8.5^{\circ} \mathrm{N}, 130^{\circ} \mathrm{E}$

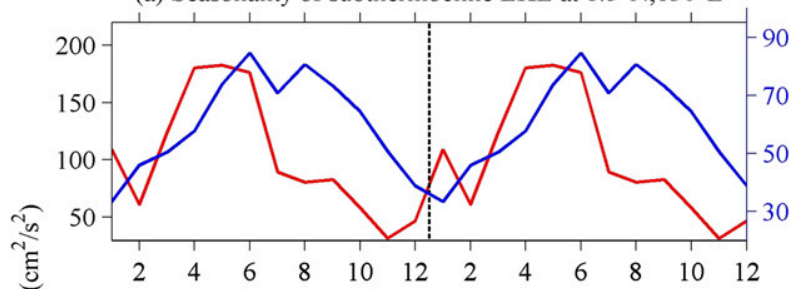

(b) Seasonality of subthermocline EKE at $12.5^{\circ} \mathrm{N}, 130^{\circ} \mathrm{E}$

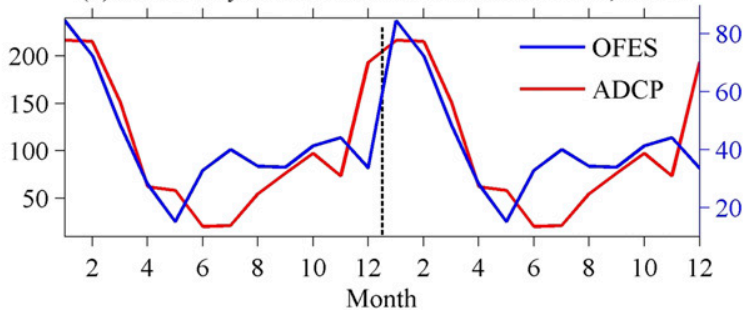

FIG. 11. Monthly mean subthermocline EKE (red) averaged between 300 and $700 \mathrm{~m}$ derived from mooring ADCP measurements at (a) $8.5^{\circ} \mathrm{N}, 130^{\circ} \mathrm{E}$ from September 2015 to November 2018 and (b) $12.5^{\circ} \mathrm{N}, 130^{\circ} \mathrm{E}$ from December 2016 to December 2018. Blue curves denote the results derived from OFES outputs (200017) at the same locations.

eddies east of the Philippine coast (e.g., Chiang and Qu 2013; Wang et al. 2014; Chiang et al. 2015). To confirm this earlier result, we calculate both the barotropic and baroclinic energy conversion rate in the subthermocline layer (300-700 m) using the OFES outputs in the western tropical Pacific during 200017. Figure 12 shows that baroclinic instability dominates in the region east of the Luzon Island and north of $13^{\circ} \mathrm{N}$, which is consistent with previous studies (e.g., Qiu et al. 2015). In the region of high subthermocline EKE east of the Philippine coast, as marked by the black box in Fig. 12, baroclinic instability also plays a major, and this is particularly so in box 1 . An elevated baroclinic energy conversion rate $(\mathrm{BCR})$ is seen (a) Annual amplitude

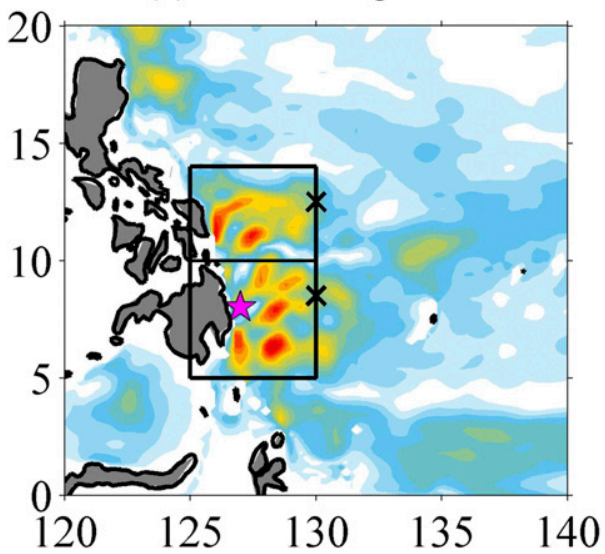

(b) Semiannual amplitude

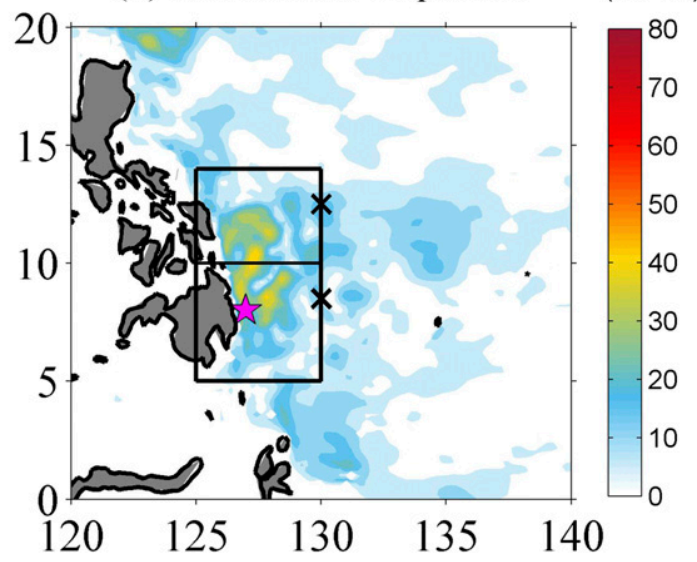

FIG. 10. Amplitude of the (a) annual and (b) semiannual cycles of the subthermocline EKE east of the Philippines derived from the harmonic analysis. The star denotes the mooring location at $8^{\circ} \mathrm{N}, 127^{\circ} \mathrm{E}$, and the black crosses denote the mooring locations at $8.5^{\circ} \mathrm{N}, 130^{\circ} \mathrm{E}$ and at $12.5^{\circ} \mathrm{N}, 130^{\circ} \mathrm{E}$. 
(a) Baroclinic conversion rate

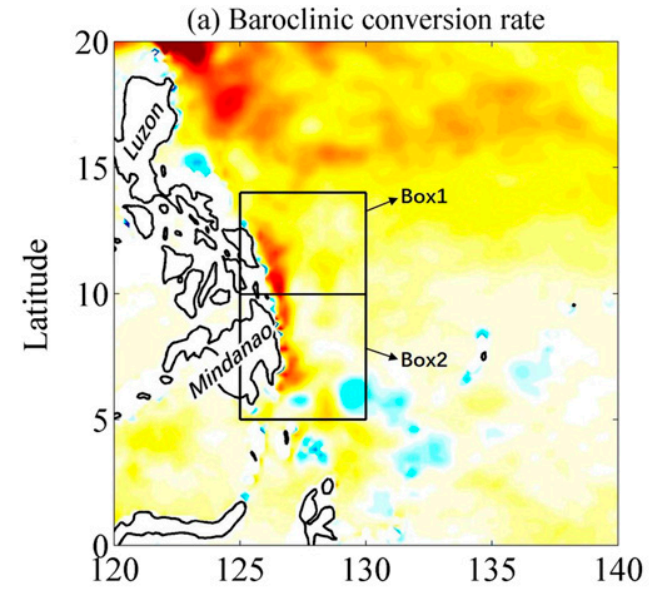

(b) Barotropic conversion rate

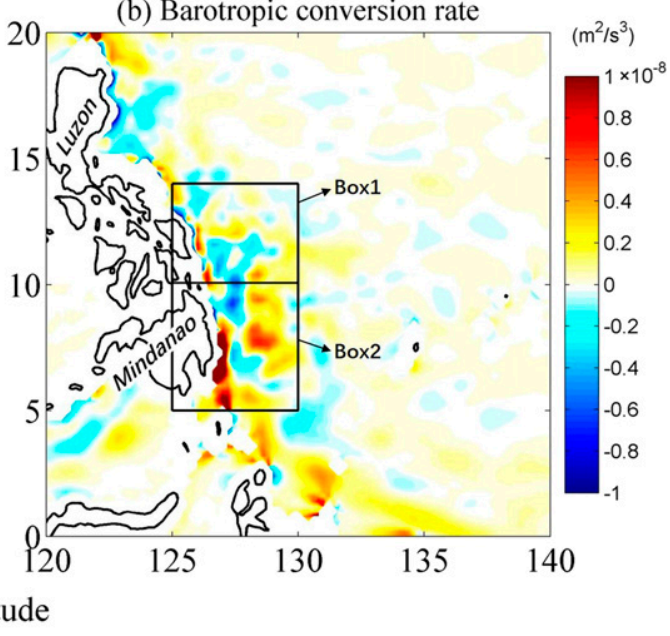

FIG. 12. Climatological mean (a) baroclinic and (b) barotropic energy conversion rate in the subthermocline layer (300-700 m) derived from OFES during 2000-17.

within a narrow longitude band of about $1^{\circ}$ off the Philippine coast, and its magnitude decreases rapidly toward the east. Barotropic instability is also energetic in box 2, where a positive barotropic energy conversion rate (BTR) extends from the coast to $130^{\circ} \mathrm{E}$, even surpassing the $\mathrm{BCR}$. The ratio of contribution from BCR and BTR to the generation of subthermocline eddies is calculated for box 1 and box 2 . The results indicate that BCR and BTR in box 1 accounts for $71 \%$ and $29 \%$ of the total energy conversion, respectively, implying the dominant role of baroclinic instability in the generation of subthermocline EKE in box 1. In box 2, these ratios change to $35 \%$ and $65 \%$, respectively, indicating that barotropic instability is the major energy source of subthermocline EKE in box 2, but contribution from baroclinic instability is not ignorable. Based on the Hybrid Coordinate Ocean Model (HYCOM) outputs, L. J. Chen et al. (2015) also investigated subthermocline eddies in this region. From their subthermocline eddy trajectories (see their Fig. 5), one can notice that most of subthermocline eddies generated south of $10^{\circ} \mathrm{N}$ do not cross $10^{\circ} \mathrm{N}$, and those generated north of $10^{\circ} \mathrm{N}$ also do not cross this latitude. The implication of this result is that subthermocline eddies north and south of $10^{\circ} \mathrm{N}$ (termed box 1 and box 2 in our study) are controlled by different dynamic processes, which is in good agreement with our conclusion above.

To identify the governing processes of seasonal modulation of subthermocline EKE east of the Philippine coast discussed in section 5, monthly mean BCR and BTR are calculated using 150-day high-pass-filtered velocities from OFES for the period 2000-17. Figure 13 shows the distribution of monthly BCR vertically averaged in the subthermocline layer (300-700 m) east of the Philippine coast. It is seen that positive BCR nearly dominates the region all the year round. In the region of high subthermocline EKE (black box), high BCR is concentrated in a narrow longitude band close to the coast, and no obvious seasonal variation is visible. The distribution of monthly BTR is shown in Fig. 14. Large BTR can be identified near the Philippine coast, especially in the region of high subthermocline EKE east of the
Mindanao Island. Even though the BTR signals are sporadic, they still show a visible seasonal variation. In box 2, strong positive BTR signal appears during May-July, and only weak BTR signal occurs during fall and winter. The seasonal cycle in box 1 shows an opposite phase to that in box 2, with relatively stronger positive BTR in winter and weaker BTR in summer.

To relate the seasonal modulation of subthermocline EKE to barotropic/baroclinic instability, we calculate the regional mean BTR and BCR in box 1 and box 2 for each month (Fig. 15). Since positive BTR indicates kinetic energy conversion from the mean flow to eddies, and positive BCR indicates potential energy conversion, we consider the positive BTR and BCR in Figs. 13 and 14 to derive the seasonal cycle of the regional mean BCR and BTR. The BTR in box 1 exhibits a significant seasonal variation (Fig. 15a), reaching its maximum of $\sim 3.4 \times 10^{-9} \mathrm{~m}^{2} \mathrm{~s}^{-3}$ in January and minimum of $\sim 0.8 \times$ $10^{-9} \mathrm{~m}^{2} \mathrm{~s}^{-3}$ in July. The BCR in box 1 shows a weaker seasonal variation, peaking in March and remaining little changed from May to the next February. The standard deviation (STD) of seasonal variation in BCR is $0.39 \times 10^{-9} \mathrm{~m}^{2} \mathrm{~s}^{-3}$, much smaller than that $\left(0.75 \times 10^{-9} \mathrm{~m}^{2} \mathrm{~s}^{-3}\right)$ of BTR. Interestingly, the seasonal variation of BTR is rather similar to that of subthermocline EKE in box 1, both of which get stronger in winter and weaker in summer. The correlation between their seasonal cycles reaches 0.77 , which is above the $95 \%$ confidence level. The maximum EKE appears in March, lagging the maximum BTR by 2 months. This difference in phase is probably due to the modulation of baroclinic instability, which approaches its maximum in March. We also calculate the contribution of BTR and $\mathrm{BCR}$ to the seasonal cycle of subthermocline EKE in box 1 , and find that the seasonal variation of BTR and BCR explains $78.7 \%$ and $21.3 \%$ of the seasonal subthermocline EKE, respectively. Therefore, it is suggested that the seasonal variation of subthermocline EKE in box 1 is mainly due to the seasonal variation of barotropic instability, though baroclinic instability is essential in the generation of subthermocline eddies in the region studied. We also tested the sensitiveness of 


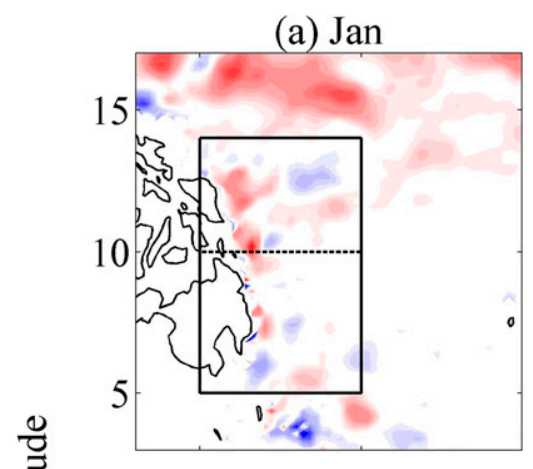

(d) Jul

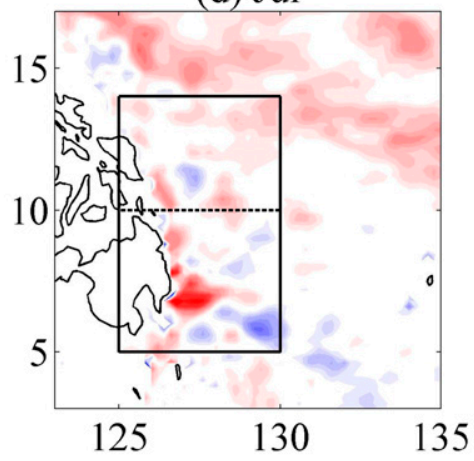

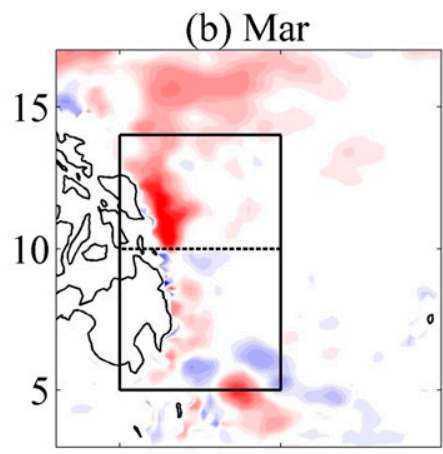

(b) Mar

(e) Sep

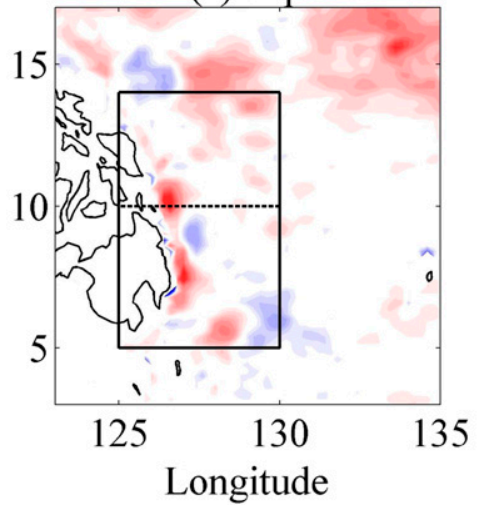

(c) May

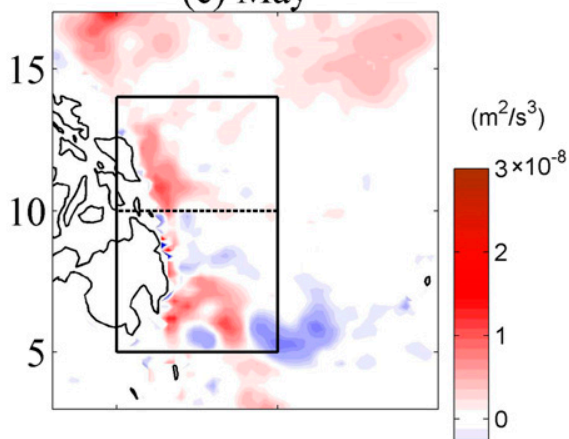

(f) Nov

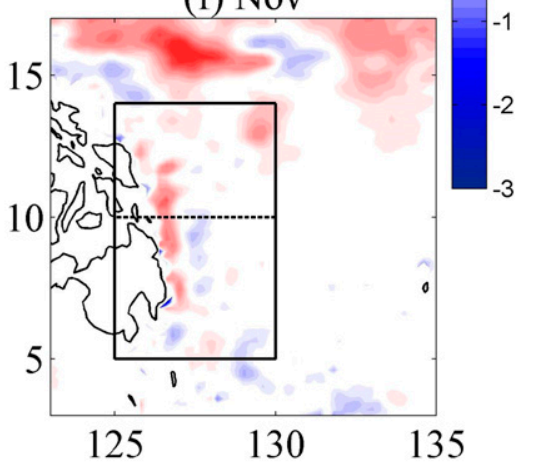

FIG. 13. Monthly mean baroclinic energy conversion rate in the subthermocline layer (300-700 m) calculated from OFES during $2000-17$.

the annual cycles of EKE, BCR and BTR to the selection of boxes 1 and 2 by using boxes with different size (not shown), and the results indicate that the annual cycles of these terms are very robust and change little with selected boxes.

Figure $15 \mathrm{~b}$ shows the seasonal cycle of regional mean BCR/BTR and subthermocline EKE in box 2. The BTR also shows an obvious seasonal variation, which peaks in May and then decreases gradually till October. The STD of seasonal variation in BTR is $0.89 \times 10^{-9} \mathrm{~m}^{2} \mathrm{~s}^{-3}$, relative to its mean value of $3.05 \times 10^{-9} \mathrm{~m}^{2} \mathrm{~s}^{-3}$. The BCR in box 2 shows a similar seasonal signal but with a weaker amplitude than BTR, reaching its maximum of $2.0 \times 10^{-9} \mathrm{~m}^{2} \mathrm{~s}^{-3}$ in June and minimum of $0.9 \times 10^{-9} \mathrm{~m}^{2} \mathrm{~s}^{-3}$ in November. The STD of seasonal variation in $\mathrm{BCR}$ is $0.36 \times 10^{-9} \mathrm{~m}^{2} \mathrm{~s}^{-3}$, relative to its mean vale of $1.44 \times 10^{-9} \mathrm{~m}^{2} \mathrm{~s}^{-3}$. The seasonal cycle of subthermocline EKE in box 2 is consistent with that of BTR, both of which reach their maxima in the late spring and early summer and minima in winter. The correlation between the two seasonal cycles is 0.78 , with BTR leading EKE by 2 months. This phase lag may be partially due to the contribution of BCR, whose seasonal cycle lags that of BTR by 1 month. The seasonal variation of BTR and BCR explains about $86 \%$ and $14 \%$ of the seasonal cycle of EKE in box 2, respectively. Therefore, we suggest that the seasonal variation of subthermocline EKE in box 2 is mainly due to the seasonal variation of barotropic instability, and baroclinic instability only slightly modulates its phase.

To figure out the underlying mechanism of the seasonal variation of barotropic instability in the subthermocline layer, we investigate the variation of subthermocline background flow east of the Philippine coast. Figure 16 shows the monthly mean velocities between 300 and $700 \mathrm{~m}$, which are derived from the 150-day low-pass-filtered velocities of OFES. A dominant feature in Fig. 16 is a seasonally varying anticyclonic eddy lying to the southeast of the Mindanao Island, which is believed to be the subthermocline part of the Halmahera Eddy (HE) (Qu et al. 1999). As mentioned in the introduction, the western tropical Pacific is characterized by a complex current system both in the surface and subthermocline layers (e.g., Lukas et al. 1996; Hu et al. 2015). Near the Halmahera Island, there exists a quasi-permanent anticyclonic eddy called the $\mathrm{HE}$ (Fig. 1), which is only well developed during the summer monsoon, when the New Guinea Coastal Current and Undercurrent recurve into the NECC (e.g., Wyrtki 1961; Fine et al. 1994). The $\mathrm{HE}$ lies at about $3^{\circ} \mathrm{N}, 130^{\circ} \mathrm{E}$ near the surface, and tilts northwestward with increasing depth, reaching the Mindanao coast on the density surface of $27.2 \sigma_{\theta}$ at about $750 \mathrm{~m}$. Its horizontal scale decreases from about $500 \mathrm{~km}$ at $50 \mathrm{~m}$ to about $300 \mathrm{~km}$ at $350 \mathrm{~m}$ (e.g., Qu et al. 1999; Kashino et al. 1999). The vertical structure of the HE derived from OFES (not shown) is consistent with observations mentioned above. $X$. Chen et al. (2015) reported that the seasonal meandering of the NECC, which is tightly linked to the seasonal cycle of the $\mathrm{HE}$, is responsible for the seasonal variation of barotropic instability, controlling the seasonal variation of local EKE in the upper $200 \mathrm{~m}$. Since the HE extends below the thermocline down to about $800 \mathrm{~m}$, its seasonal variation may also modulate 
(a) Jan

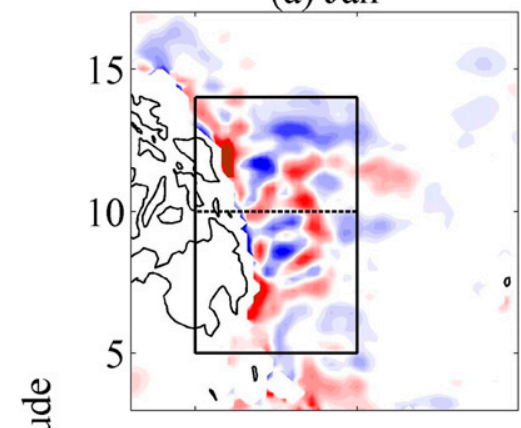

(d) Jul

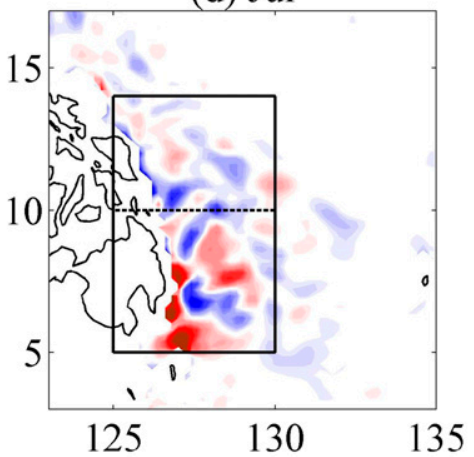

(b) Mar

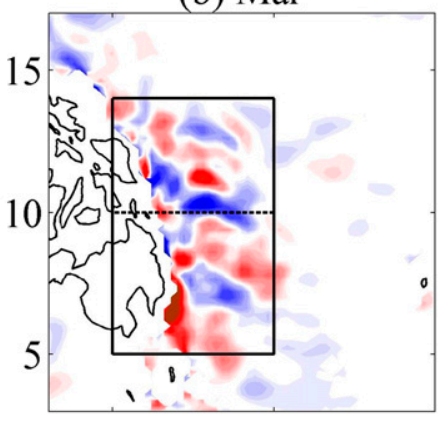

(e) Sep

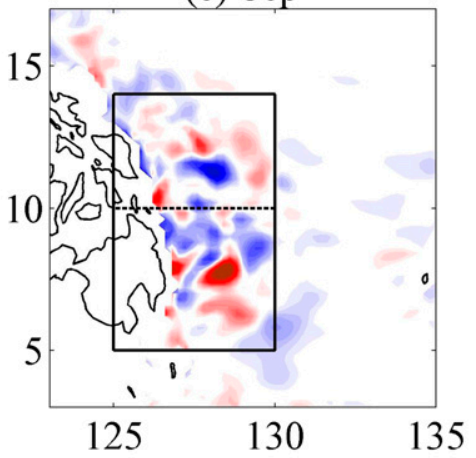

(c) May

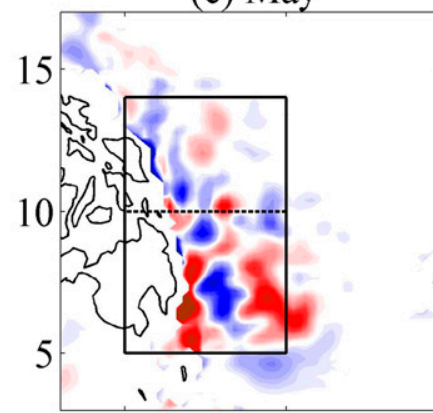

(f) Nov

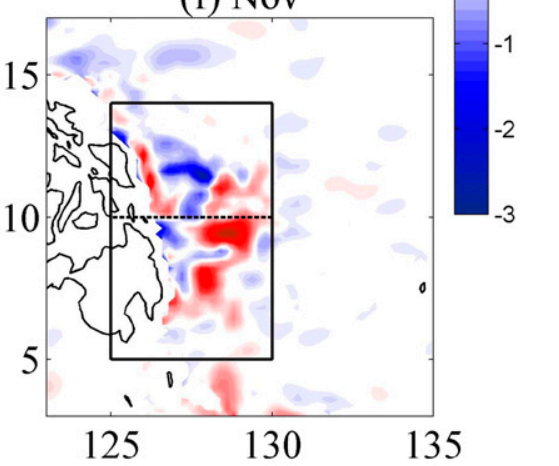

\section{Longitude}

FIG. 14. As in Fig. 13, but for the barotropic energy conversion rate.

the subthermocline EKE east of Mindanao Island through barotropic instability. We therefore examine the seasonal variation of the subthermocline $\mathrm{HE}$ in the following.

As shown in Fig. 16, the subthermocline HE southeast of the Mindanao Island exhibits significant seasonal variations. It is obviously strong in the first half of the year and weak in the second half. The HE starts to move northward in January and strengthen gradually afterward, reaching its maximum strength and northernmost latitude of about $7.5^{\circ} \mathrm{N}$ in April and May. Then, the HE decays gradually, and becomes an anticyclonic meander in November. Similar to X. Chen et al. (2015), the northward movement and enhancement of the subthermocline HE from January to May are accompanied with increasing nonlinear shears of the subthermocline horizontal velocity
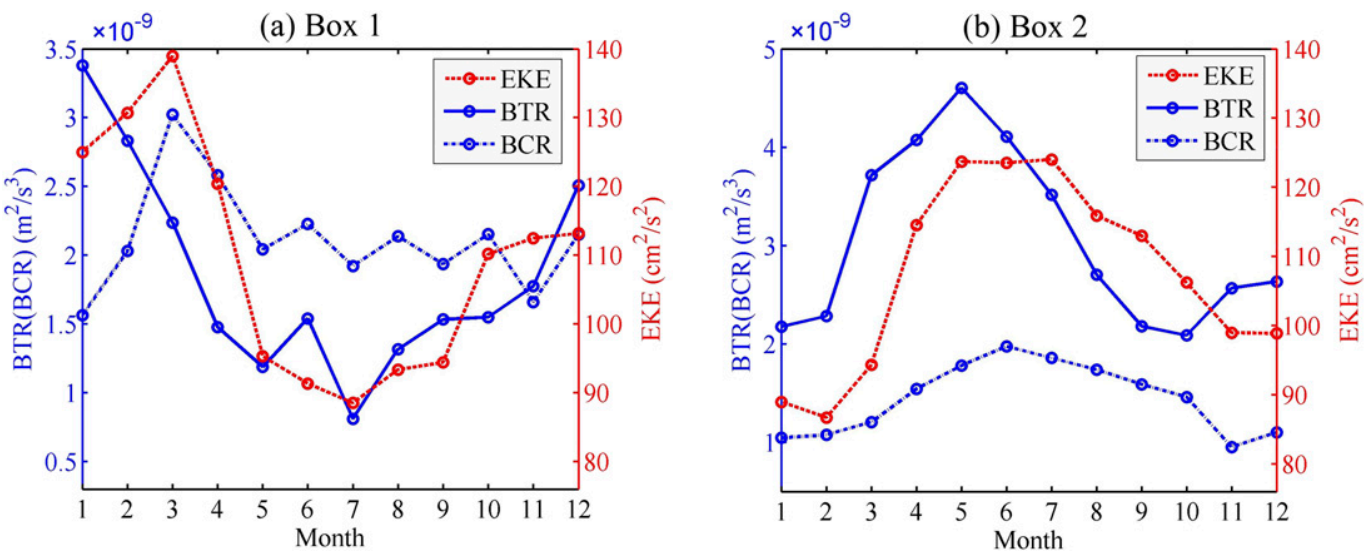

FIG. 15. (a) Seasonal variation of regional mean barotropic energy conversion rate (BTR; blue solid), baroclinic energy conversion rate (BCR; blue dashed), and EKE (red) in the subthermocline layer (300-700 $\mathrm{m})$ in box $1\left(125^{\circ}-130^{\circ} \mathrm{E}, 10^{\circ}-14^{\circ} \mathrm{N}\right)$, calculated with OFES outputs; (b) as in (a), but for box $2\left(125^{\circ}-130^{\circ} \mathrm{E}, 5^{\circ}-10^{\circ} \mathrm{N}\right)$. 
(a) Jan

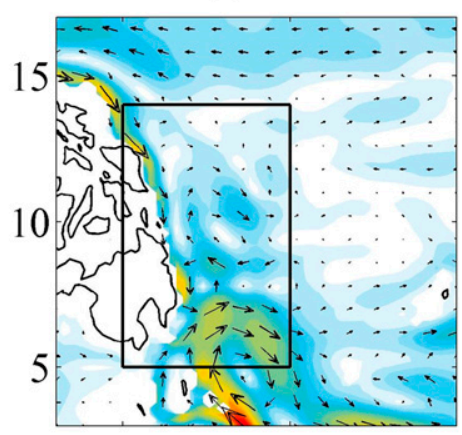

(d) Jul

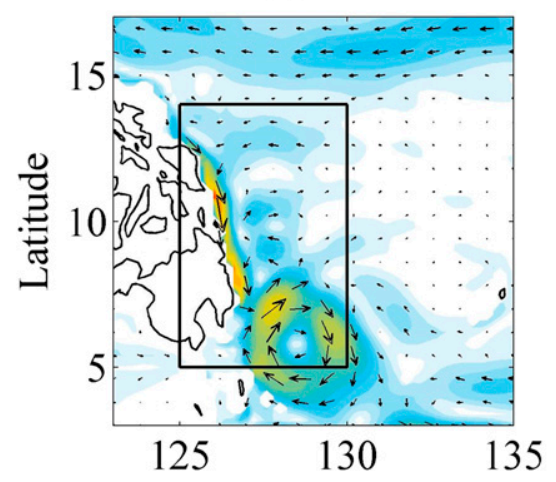

(b) Mar

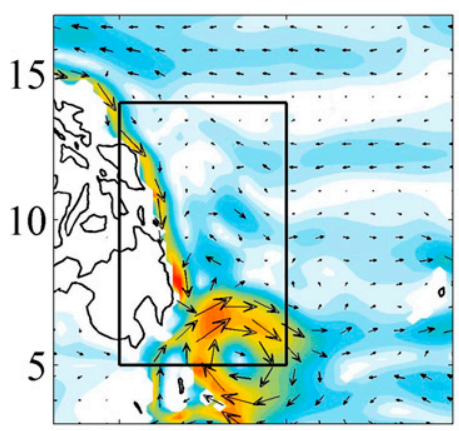

(e) Sep

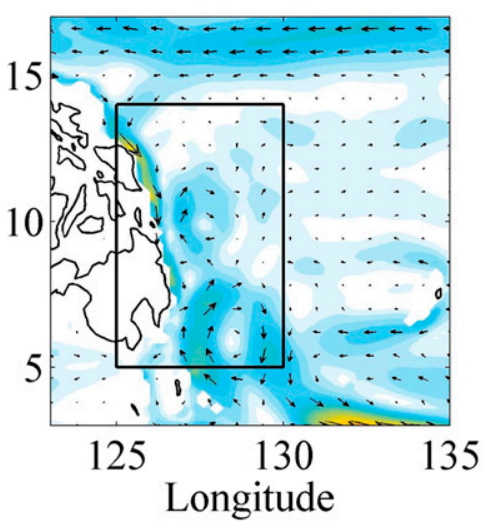

(c) May

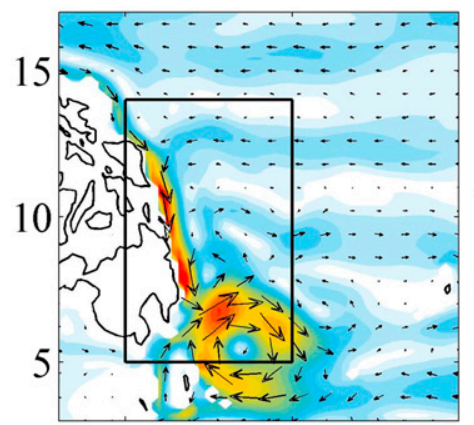

(f) $\mathrm{Nov}$

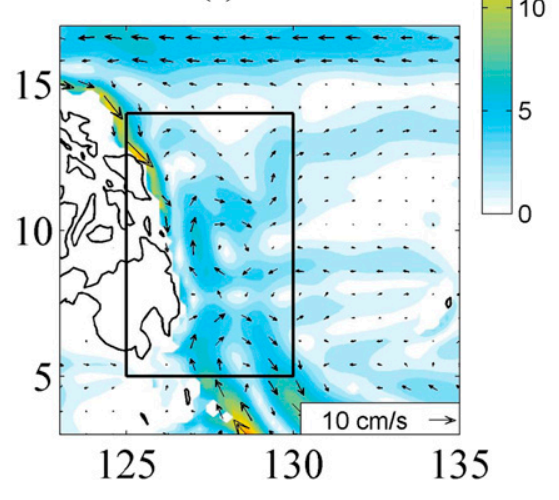

FIG. 16. Monthly mean velocity (vectors) and speed (color) in the subthermocline layer (300-700 m), calculated with the OFES outputs during 2000-17.

field, inducing greater energy conversion from the mean kinetic energy to subthermocline eddies through barotropic instability. The increase of subthermocline EKE and BTR in box 2 east of the Mindanao Island as shown in Fig. 15b agrees well with the HE variations mentioned above. The subthermocline HE weakens from May to November, and the corresponding nonlinear shear of the subthermocline horizontal velocity field weakens, producing decreases of the BTR and subthermocline EKE in box 2 (Fig. 15b). Therefore, it is concluded that the seasonal cycle of the subthermocline HE in both intensity and location induces the seasonal variation of barotropic instability, which further modulates the seasonality of subthermocline EKE in box 2 east of the Mindanao Island.

As mentioned above, the seasonal cycle of subthermocline EKE and BTR in box 1 is nearly in opposite phase to that in box 2 (Fig. 15). So, we have reason to believe that there are different mechanisms underlying the seasonal variation of BTR between the two boxes. As shown in Fig. 16, the subthermocline flow pattern east of the Philippine coast is dominated by alternating zonal jets. To further illustrate the current structure in the region, Fig. 17 shows a meridional section of climatological mean zonal velocity crossing those zonal jets. Box 1 is located between $10^{\circ}$ and $14^{\circ} \mathrm{N}$, corresponding to the latitude range of the eastward flowing NEUC jets with the westward flowing NEC above it (Fig. 17). The NEUC jets have been observed by Argo floats and moorings (e.g., Qiu et al. 2013; Wang et al. 2015; Zhang et al. 2017), presumably as a result of triad baroclinic Rossby wave interactions (Qiu et al. 2013). OFES is able to simulate the NEUC jets properly (Qiu et al. 2013). Based on the OFES outputs, Chiang et al. (2015) suggested that the subthermocline eddies east of the Philippine coast were generated by interactions between meridional shift of the NEC and NEUC, and their interactions with the topography through both baroclinic and barotropic instability. Therefore, it is likely that the seasonal variation of

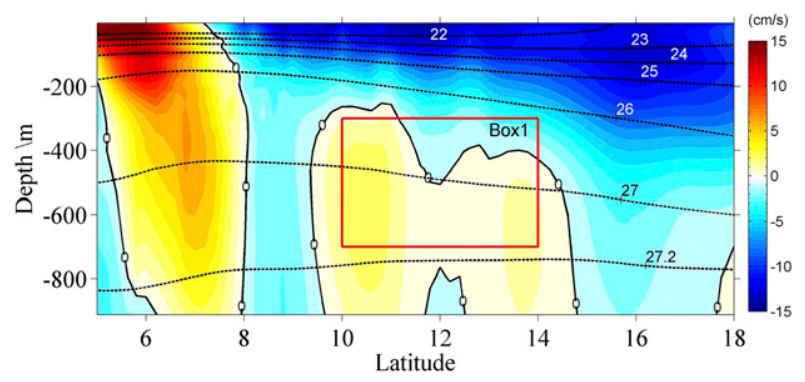

FIG. 17. Climatological mean zonal velocity (color) averaged between $125^{\circ}$ and $130^{\circ} \mathrm{E}$, calculated with OFES outputs during 2000-17; dashed lines denote isopycnals, and the red box shows the vertical and meridional range of box 1 . 
subthermocline EKE and BTR in box 1 is related to the NEUC variation in the subthermocline layer.

Figure 18 shows the seasonal variation of NEUC transport from OFES. Here, the NEUC transport is defined as the integral of all eastward flows in the upper $900 \mathrm{~m}$ between $9^{\circ}$ and $15^{\circ} \mathrm{N}$, and the velocity has been zonally averaged between $125^{\circ}$ and $130^{\circ} \mathrm{E}$ and filtered with a 150-day low-pass filter to remove mesoscale eddy signals. The NEUC is weak in summer and strong in late fall and winter, corresponding well with the seasonal cycle of BTR in box 1 (Fig. 18). When the NEUC is in a strong phase, there are stronger horizontal shears between the NEUC and surrounding subthermocline currents, indicating a higher BTR with more kinetic energy being converted from the mean flow to subthermocline eddies through barotropic instability. The opposite occurs when the NEUC is in a weak phase. Therefore, we suggest that the seasonal variation of subthermocline EKE and BTR in box 1 is associated with the seasonal cycle of the NEUC transport.

\section{Conclusions and discussion}

Based on the OFES outputs combined with mooring ADCP measurements, the generation and seasonal variation of subthermocline EKE east of the Philippine coast are investigated. It is revealed that baroclinic instability is the dominant factor in the generation of subthermocline eddies in this region, while contribution from barotropic instability is nonignorable. The contribution from barotropic instability even overcome that from baroclinic instability in the region east of the Mindanao Island. The seasonal cycle of the subthermocline EKE is variable with space. The EKE north of $10^{\circ} \mathrm{N}$ (box 1) is stronger in boreal spring and weaker in summer, while the EKE south of $10^{\circ} \mathrm{N}$ (box 2) exhibits an opposite phase. Further analysis indicates that the seasonal cycle of subthermocline EKE in both boxes is primarily modulated by the seasonal variation of barotropic instability, but the associated physical processes are different between the two boxes. In box 1 , the barotropic instability results from the horizontal velocity shears between the NEUC and surrounding subthermocline currents. When the NEUC is stronger, there is more kinetic energy converted from the mean flow to subthermocline eddies, and vice versa. But in box 2 , the seasonal variation of the $\mathrm{HE}$ dominates the seasonal cycle of barotropic energy conversion rate. A stronger $\mathrm{HE}$ corresponds to greater horizontal velocity shears or nonlinear shears, with more kinetic energy being converted from the mean flow to subthermocline eddies through barotropic instability.

In addition, it is worth noting that the most striking feature in the western tropical Pacific Ocean circulation is the bifurcation of the NEC, which splits into the northward flowing Kuroshio and the southward flowing $\mathrm{MC}$ at about $14^{\circ} \mathrm{N}$ when impinging on the Philippine coast (e.g., Fine et al. 1994; Lukas et al. 1996; Hu et al. 2015). The bifurcation latitude of the NEC varies significantly on the seasonal time scale, and previous studies based on hydrographic data and satellite altimeter measurements have shown that the NEC bifurcates at the northernmost position in boreal winter and southernmost position in boreal summer (e.g., Qiu and Lukas 1996; Qu and

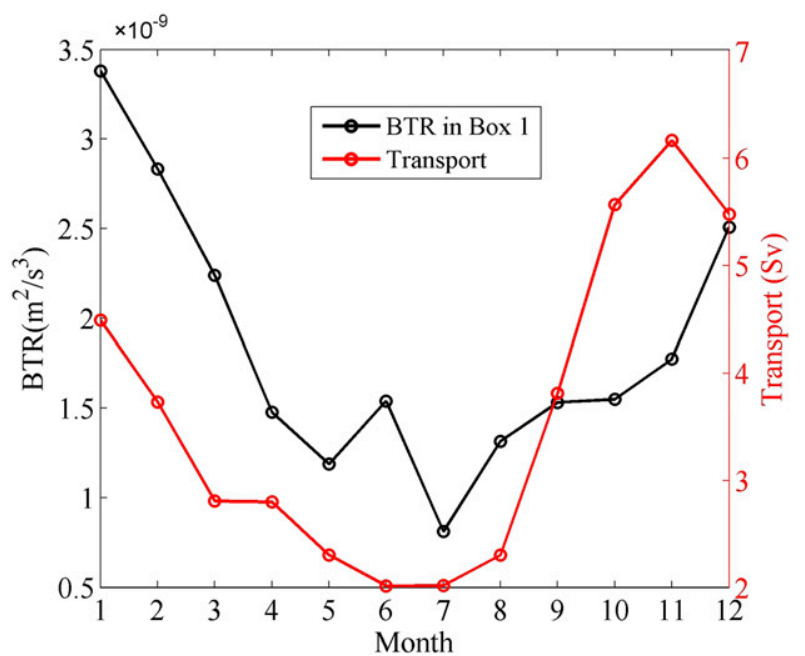

FIG. 18. Seasonal variation of the NEUC transport (red) averaged between $9^{\circ}$ and $15^{\circ} \mathrm{N}$ and barotropic energy conversion rate (black) in the subthermocline layer $(300-700 \mathrm{~m})$ in box 1 , calculated with OFES outputs from 2000 to 2017.

Lukas 2003; Chen and $\mathrm{Wu}$ 2011). The variation of the NEC bifurcation latitude is closely associated with the redistribution of water mass, heat, and salt from the NEC to the MC and the Kuroshio, and plays a pivotal role in the modulation of the tropical and subtropical gyres. The seasonally varying bifurcation of the NEC may potentially influence the seasonal cycle of the subthermocline EKE east of the Philippine coast. To address this issue, we have checked the NEC bifurcation latitude and its variation. In the climatological mean, the bifurcation latitude shifts northward with increasing depth from about $13.3^{\circ} \mathrm{N}$ near the surface to north of $20^{\circ} \mathrm{N}$ at the depth of $1000 \mathrm{~m}$ (Qu and Lukas 2003). In the subthermocline layer (300-700 m), the NEC bifurcation is located north of $16^{\circ} \mathrm{N}$, and can reach as far north as $17.8^{\circ} \mathrm{N}$ during November to January (Qu and Lukas 2003), which is outside of the high subthermocline EKE area east of the Philippine coast. Therefore, the seasonal immigration of the NEC bifurcation may have little influence on the seasonal variation of the subthermocline EKE, and further investigations are needed in future studies.

Acknowledgments. The authors are grateful to Dr. Bo Qiu for useful discussion on this topic. Two anonymous reviewers are also greatly appreciated for their insightful comments. L. Zhang, Y. Hui, and D. Hu are supported by the National Natural Science Foundation of China (41776021), the National Key Research and Development Program of China (2020YFA0608801), the Strategic Priority Research Program of the Chinese Academy of Sciences (XDB42010102), the National Natural Science Foundation of China (41730534, 41421005), the National Key Research and Development Program of China (2017YFA0603202 and 2012YQ12003907). Mooring and CTD data were collected on board of R/V KeXue implementing the open research cruise NORC2019-09 supported by the NSFC Shiptime Sharing Project (41849909) and 
the Major Project of Science and Technology Innovation of Shan Dong (2018SDKJ0105).

Data availability statement. The mooring ADCP data are available at the NPOCE website (http://npoce.org.cn/), and OFES data are downloaded from the Asia Pacific Data Research Center (APDRC) website.

\section{REFERENCES}

Chelton, D. B., R. A. Deszoeke, M. G. Schlax, K. E. Naggar, and N. Siwertz, 1998: Geographical variability of the first baroclinic Rossby radius of deformation. J. Phys. Oceanogr., 28, 433-460, https://doi.org/10.1175/1520-0485(1998)028<0433: GVOTFB $>2.0 . \mathrm{CO} ; 2$.

Chen, L. J., Y. L. Jia, and Q. Y. Liu, 2015: Mesoscale eddies in the Mindanao Dome region. J. Oceanogr., 71, 133-140, https:// doi.org/10.1007/s10872-014-0255-3.

Chen, X., B. Qiu, S. M. Chen, Y. Q. Qi, and Y. Du, 2015: Seasonal eddy kinetic energy modulations along the North Equatorial Countercurrent in the western Pacific. J. Geophys. Res. Oceans, 120, 6351-6362, https://doi.org/10.1002/2015JC011054.

Chen, Z. H., and L. X. Wu, 2011: Dynamics of the seasonal variation of the North Equatorial Current bifurcation. J. Geophys. Res., 116, C02018, https://doi.org/10.1029/2010JC006664.

Chiang, T. L., and T. D. Qu, 2013: Subthermocline eddies in the western equatorial Pacific as shown by an eddy-resolving OGCM. J. Phys. Oceanogr., 43, 1241-1253, https://doi.org/ 10.1175/JPO-D-12-0187.1.

—, C. R. Wu, T. D. Qu, and Y. C. Hsin, 2015: Activities of 5080 day subthermocline eddies near the Philippine coast. J. Geophys. Res. Oceans, 120, 3606-3623, https://doi.org/ 10.1002/2013JC009626.

Dutrieux, P., 2009: Tropical western Pacific currents and the origin of intraseasonal variability below the thermocline. Ph.D. thesis, University of Hawai'i at Mānoa, 140 pp.

Fine, R. A., R. Lukas, F. M. Bingham, M. J. Warner, and R. H. Gammon, 1994: The western equatorial Pacific: A water mass crossroads. J. Geophys. Res., 99, 25 063-25 080, https://doi.org/ 10.1029/94JC02277.

Firing, E., Y. Kashino, and P. Hacker, 2005: Energetic subthermocline currents observed east of Mindanao. Deep-Sea Res. II, 52, 605-613, https://doi.org/10.1016/j.dsr2.2004.12.007.

Hu, D. X., and Coauthors, 2015: Pacific western boundary currents and their roles in climate. Nature, 522, 299-308, https://doi.org/ 10.1038/nature14504.

— , and Coauthors, 2020: Review on observational studies of western tropical Pacific Ocean circulation and climate. J. Ocean. Limnol., 38, 906-929, https://doi.org/10.1007/s00343-020-0240-1.

$\mathrm{Hu}, \mathrm{S}$. J., and Coauthors, 2018: Spatiotemporal features of intraseasonal oceanic variability in the Philippine Sea from mooring observations and numerical simulations. J. Geophys. Res. Oceans, 123, 4874-4887, https://doi.org/10.1029/2017JC013653.

Kashino, Y., H. Watanabe, B. Herunadi, M. Aoyama, and D. Hartoyo, 1999: Current variability at the Pacific entrance of the Indonesian throughflow. J. Geophys. Res., 104, 11 021-11 035, https://doi.org/10.1029/1999JC900033.

Lukas, R., T. Yamagata, and J. P. McCreary, 1996: Pacific lowlatitude western boundary currents and the Indonesian throughflow. J. Geophys. Res., 101, 12 209-12 216, https:// doi.org/10.1029/96JC01204.

Masumoto, Y., and Coauthors, 2004: A fifty-year eddy-resolving simulation of the world ocean-Preliminary outcomes of OFES (OGCM for the Earth Simulator). J. Earth Simul., 1, 35-56.
Nan, F., F. Yu, C. J. Wei, Q. Ren, and C. H. Fan, 2017: Observations of an extra-large subsurface anticyclonic eddy in the northwestern Pacific subtropical gyre. J. Mar. Sci. Res. Dev., 7, 235, https://doi.org/10.4172/2155-9910.1000234.

Pelland, N. A., C. C. Eriksen, and C. M. Lee, 2013: Subthermocline eddies over the Washington continental slope as observed by Seagliders, 2003-09. J. Phys. Oceanogr., 43, 2025-2053, https:// doi.org/10.1175/JPO-D-12-086.1.

Qiu, B., 1999: Seasonal eddy field modulation of the north pacific subtropical countercurrent: TOPEX/Poseidon observations and theory. J. Phys. Oceanogr., 29, 2471-2486, https://doi.org/ 10.1175/1520-0485(1999)029<2471:SEFMOT >2.0.CO;2.

__ , and R. Lukas, 1996: Seasonal and interannual variability of the North Equatorial Current, the Mindanao Current and the Kuroshio along the Pacific western boundary. J. Geophys. Res., 101, 12315-12 330, https://doi.org/10.1029/ 95JC03204.

_ , S. M. Chen, and H. Sasaki, 2013: Generation of the North Equatorial Undercurrent jets by triad baroclinic Rossby wave interactions. J. Phys. Oceanogr., 43, 2682-2698, https://doi.org/ 10.1175/JPO-D-13-099.1.

,,-- D. L. Rudnick, and Y. J. Kashino, 2015: A new paradigm for the North Pacific subthermocline low-latitude western boundary current system. J. Phys. Oceanogr., 45, 2407-2423, https://doi.org/10.1175/JPO-D-15-0035.1.

Qu, T. D., and R. Lukas, 2003: The bifurcation of the North Equatorial Current in the Pacific. J. Phys. Oceanogr., 33, 5-18, https://doi.org/ 10.1175/1520-0485(2003)033<0005:TBOTNE $>2.0 . C O ; 2$.

— - H. Mitsudera, and T. Yamagata, 1999: A climatology of the circulation and water mass distribution near the Philippine coast. J. Phys. Oceanogr., 29, 1488-1505, https://doi.org/ 10.1175/1520-0485(1999)029<1488:ACOTCA>2.0.CO;2.

—, T. L. Chiang, C. R. Wu, P. Dutrieux, and D. X. Hu, 2012: Mindanao current/undercurrent in an eddy-resolving GCM. J. Geophys. Res., 117, C06026, https://doi.org/10.1029/ 2011JC007838.

Sasaki, H., M. Nonaka, Y. Masumoto, Y. Sasai, H. Uehara, and H. Sakuma, 2008: An eddy-resolving hindcast simulation of the quasiglobal ocean from 1950 to 2003 on the Earth Simulator. High Resolution Numerical Modelling of the Atmosphere and Ocean, K. Hamilton and W. Ohfuchi, Eds., Springer, 157-185, https://doi.org/10.1007/978-0-387-49791-4_10.

Wang, F., N. Zang, Y. L. Li, and D. X. Hu, 2015: On the subsurface countercurrents in the Philippine Sea. J. Geophys. Res. Oceans, 120, 131-144, https://doi.org/10.1002/2013JC009690.

_, Y. L. Li, and J. N. Wang, 2016a: Intraseasonal variability of the surface zonal currents in the western tropical Pacific Ocean: Characteristics and mechanisms. J. Phys. Oceanogr., 46, 3639-3660, https://doi.org/10.1175/JPO-D-16-0033.1.

— intermediate waters east of the Philippines. Geophys. Res. Lett., 43, 7059-7065, https://doi.org/10.1002/2016GL069323.

Wang, Q. Y., F. G. Zhai, F. J. Wang, and D. X. Hu, 2014: Intraseasonal variability of the subthermocline current east of Mindanao. J. Geophys. Res. Oceans, 119, 8552-8566, https:// doi.org/10.1002/2014JC010343.

Wyrtki, K., 1961: Physical oceanography of the southeast Asian waters. NAGA Rep. 2, Scripps Institution of Oceanography, 195 pp., https://escholarship.org/uc/item/49n9x3t4.

Xu, A. Q., F. Yu, and F. Nan, 2019: Study of subsurface eddy properties in northwestern Pacific Ocean based on an eddy-resolving OGCM. Ocean Dyn., 69, 463-474, https://doi.org/10.1007/ s10236-019-01255-5. 
Yang, C. C., X. Chen, X. H. Cheng, and B. Qiu, 2020: Annual versus semi-annual eddy kinetic energy variability in the Celebes Sea. J. Oceanogr., 76, 401-418, https://doi.org/10.1007/ s10872-020-00553-7.

Zhang, L. L., D. X. Hu, S. J. Hu, F. Wang, F. J. Wang, and D. L. Yuan, 2014: Mindanao Current/Undercurrent measured by a subsurface mooring. J. Geophys. Res. Oceans, 119, 3617-3628, https://doi.org/10.1002/2013JC009693.
_, F. J. Wang, Q. Y. Wang, S. J. Hu, F. Wang, and D. X. Hu, 2017: Structure and variability of the North Equatorial Current/ Undercurrent from mooring measurements at $130^{\circ} \mathrm{E}$ in the western Pacific. Sci. Rep., 7, 46310, https://doi.org/10.1038/srep46310.

Zhu, Y. N., B. Qiu, X. P. Lin, and F. Wang, 2018: Interannual eddy kinetic energy modulations in the Agulhas Return Current. J. Geophys. Res. Oceans, 123, 6449-6462, https://doi.org/ 10.1029/2018JC014333. 